\title{
Viscosity of nanofluids-A Review
}

\author{
A K Patra', M K Nayak², A Misra ${ }^{3}$ \\ ${ }^{1}$ Department of Mathematics, Govt. Autonomous College, Rourkela, Odisha, India \\ ${ }^{2}$ Department of Physics, Radhakrishna Institute of Technology and Engineering, Bhubaneswar- \\ 752057, Odisha, India \\ ${ }^{3}$ Department of Mathematics, Centurian University of Technology and Management, \\ Paralakhemundi, Gajapati-761211, Odisha, India
}

Received: 28 February 2020; Received in revised form: 21 May 2020; Accepted: 3 June 2020; Published online 30 June 2020

(C) Published at www.ijtf.org

\begin{abstract}
In the present study a comprehensive review on rheological characteristics of nanofluids for their advanced heat transfer applications has been conducted and presented. The present article critically summarizes the recent research developments regarding the theoretical and experimental investigations about viscosity of different nanofluids. In addition, different reasonably attractive theoretical models and experimental correlations are explored and well discussed. Moreover, the current study analyzes several factors those strongly influencing viscosity of nanofluids include solid volume fraction, temperature, particle size, particle shape, different base fluids, surfactants addition, ultrasonication, nanoclustering and $\mathrm{pH}$ value. Important theoretical and experimental results from many researchers and predictions from a number of viscosity models are compared and discussed with appropriate justification. Most results reveal that the viscosity of nanofluid upsurges due to an increase in particle concentration while that belittles with diminishing temperature. Augmentation of nanoadditives size leads to decreasing/increasing of nanofluid fluid viscosity. For the most nanofluids, Newtonian behavior is observed for low volume fractions, shear rates, concentrations and viscosity while non-Newtonian behavior is visualized for high volume fractions, shear rates, concentrations and viscosity. Nanofluids used carbon nanotubes are almost non-Newtonian in nature while nanofluids not involving carbon nanotubes are mostly Newtonian. Finally, the research challenges and needs in this important area of nanofluids are also highlighted.
\end{abstract}

Keywords: Nanofluids; Viscosity; Nanoparticle volume fraction; nanoclustering; Particle loading; Heat transfer. 
A.K. Patra et al.

International Journal of Thermofluid Science and Technology (2020), Volume 7, Issue 2, Paper No. 070202

\section{Introduction}

Nanofluids are a new generation of heat transfer fluids that have attracted researchers' attention from diversified fields due to their anomalous thermal behavior and tremendous potential in diversified aspects of engineering applications. The nanofluids are novel type of fluids in which nanoparticles [nano meter-sized particles (smaller than $100 \mathrm{~nm}$ )] such as copper $(\mathrm{Cu})$, nickel $(\mathrm{Ni})$, aluminium $(\mathrm{Al})$, Silver $(\mathrm{Ag})$, titanium oxide $\left(\mathrm{TiO}_{2}\right)$, aluminium oxide $\left(\mathrm{Al}_{2} \mathrm{O}_{3}\right)$, copper oxide $(\mathrm{CuO})$, iron oxide $\left(\mathrm{Fe}_{3} \mathrm{O}_{4}\right)$, etc. are mixed with the base fluids/conventional fluids such as water, kerosene, ethylene glycol, light oil etc. through proper dilution and suspension. Simply, we may say that nanofluid is a suspension of solid nanoparticles (1-100 nm) in conventional fluids. It was Choi [1] who invented the nanofluid experimentally through proper suspension and dilution of nanoparticles with base fluids in 1995 at Argonne National Laboratory, USA.

From the research it is well known that micron-size particles mixed with base fluids to lead to poor stability and sedimentation of the micron-size particles, erosion, clogging of the channels, and the enhanced fluid pumping power in heat transfer systems. Such drawbacks impede the microfluids in heat transfer applications [2-3]. Later, nanofluids concept has emerged to overcome these experienced problems. Although dispersion of nanosize particles are expected to exhibit more stability, larger surface area to volume ratio and the higher surface energy of nano-size particles caused the aggregation and sedimentation of nanoparticles. Sustainment of the enhanced thermal conductivity of nanofluids is due to the dispersion stability. In order to enhance the stability of the colloidal suspensions, merely the synthesis of nanofluids by simply mixing of solid particles with the hosting fluid is not enough rather it involves different physical and chemical treatments for the purpose [4-8].

The study of heat transfer has become important industrially for determining the quality of final products with desired characteristics which greatly depends on the rate of heat transfer /rate of cooling between the fluid and solid surface. In view of diversified industrial usefulness, conventional fluids have received much attention by many vibrant researchers in the last quarter century. They do not have enough heat transfer capability. Such drawbacks of base fluids restrict their use as cooling agent in many heat flow devices include electronics devices, material processing, solar thermal collectors etc. Various methods of preparation, addition of surfactants for enhancement of stability and use of ultrasonication are used along with proper dilution and suspension that lead to the formation of nanofluids of enormous heat transfer capability. So, nanofluid is a fluid of remarkable thermo-physical properties, superior transport properties and significant enhancement in heat transfer capability. Because of high heat transfer capability, nanofluids lead to high performance with respect to improved efficiency, reduction in size and fabrication cost and better safety margin of heat transfer equipments/thermal systems. In view of high heat transfer capability of nanoparticles compared to conventional base fluids, nanofluids are served as better coolants in computers and nuclear reactors, cancer therapy, safer surgery, lubricants, heat exchangers, microchannel heat sinks and several electronic devices for use in military sectors, vehicles and transformers, in designing the waste heat removal equipment, major manufacturing industries including materials and chemicals, oil and gas, food and drink, paper and printing, wound treatment, sterilized devices, gastric medications and great importance in the processes such as targeted drug release, asthma treatment, synergistic effects in immunology, elimination of tumors with hyperthermia etc. [9-15]. Therefore, the physical properties including thermal 
A.K. Patra et al.

International Journal of Thermofluid Science and Technology (2020), Volume 7, Issue 2, Paper No. 070202

conductivity and viscosity are essential parameters to investigate the great potential for heat transfer enhancement of flowing liquid. The knowledge of fluid flow properties, especially viscosity is a very important feature of any nanofluid since it is critically related to the pumping power needed for applications of nanofluids in the fluid flow system involved in heat exchangers.

Viscosity is one of the most important thermophysical properties of nanofluids have significant contribution to the determination of the fluid flow and heat transfer. The viscosity is one of the most important transport properties of nanofluids in the applications where nanofluids are expected to be used as a new class of heat transfer fluids such as heat exchangers or cooling systems [16-18]. The influence of viscosity on the velocity of the nanofluid will modify the temperature distribution and hence affects heat transfer characteristic of nanofluids. The viscosity of nanofluid essentially determines the flow resistance, pumping power and even the usability of nanofluids. The dimensionless numbers associated with heat transfer viz. Nusselt and Reynolds numbers are directly related to the viscosity of nanofluids [19-22]. Therefore, the viscosity should be determined by experimental or numerical means before design a heat transfer system with nanofluids as the working fluid.

Nanofluids are characterized by higher viscosity compared to their base fluids and it further upsurges with increasing concentration of nanoparticles [23]. The results regarding the viscosity of nanofluids cannot be predicted from the existing classical models. Further, it is fact that almost all recently proposed empirical correlations achieved by fitting their own experimental results are neither widely accepted nor suitable for other types of nanofluids [24-25]. An intensive study of literature reveals that there is scattering/disparities and inconsistency about the results of viscosity of nanofluids. The rationally behind such inconsistency and scattered results are due to several issues such as adopting different particle size, particle shape, $\mathrm{pH}$ of the suspension, purity of nanoparticles, temperature, different kinds of measuring equipment or geometry, considering change in shear rate, scale of agglomeration, and different dispersion and sample preparation methods [26-27].

In the past decades, the effects of influential pertinent physical parameters such as concentration of nanoparticles, temperature, base fluid types, dispersion, and particle size, type and shape on the viscosity of nanofluids have been studied for exploiting their potential in a wide range of applications [16]. In fact, the volume of studies carried on viscosity is much lower compared to the studies on thermal conductivity. However, regarding the costeffectiveness parameter due to nanofluids usage studies on the viscosity have increased day by day in parallel with the studies on the thermal conductivity [20]. In some research, it is visualized that nanofluids even with high viscosity exhibit better heat transfer than the conventional heat transfer fluids used as base fluids. Prasher et al. [20] adopted a thermal and hydraulic analysis in their investigation and declared that the relative increase in the viscosity is around four times larger than the relative increase in thermal conductivity of nanofluids which are considered to be better than the base liquid in heat transfer applications. Such drawbacks that nanofluids exhibiting higher viscosity compared to their base fluids could be compensated satisfactorily through other significantly enhanced thermal properties like thermal conductivity, heat transfer coefficient, and critical boiling heat flux making them fluids of next-generation of coolants [15,20]. 


\section{A.K. Patra et al.}

International Journal of Thermofluid Science and Technology (2020), Volume 7, Issue 2, Paper No. 070202

Motivated by above significant usefulness and relevant applications of nanofluids in diversified fields the main objective of the present study is to provide a comprehensive reviews on the latest developed classical and experimental viscosity models of nanofluids. The impact of several influential factors such as concentration of nanoparticles, temperature, base fluid types, dispersion, and particle size, type and shape on viscosity of each type of nanofluids that would be helpful updating the information for the researchers in this field has been explicitly reviewed. Important theoretical and experimental results from various research groups and predictions from many viscosity models are also compared and discussed. The novelty of the present study is to reveal the viscosity mechanisms responsible for the heat transfer coefficient behaviors. The present review article also reveals the issues that account for the existing scattering/disparities and inconsistency about the results of viscosity of nanofluids. At last, the present article focuses on the challenges and research needs in the indispensible areas of nanofluids.

\section{Rheological Behavior of Nanofluids}

An overview of the research conducted in the past decades reveals that Rheology of a nanofluid identifies its flow nature and affects the pressure drop in flow systems is perceived as its most significant outcome. Naturally, the rheological behavior of nanofluids can be obtained from the relationship between shear rate and shear stress or apparent viscosity. In fact, for Newtonian nature, the shear stress exhibits linear relation and the apparent viscosity remains constant with shear rate. On the other hand, fluids that show shear rate-dependent apparent viscosity or nonlinear relation between the shear rate and shear stress are nonNewtonian. Studies on Rheology of nanofluids convey that these fluids can have both Newtonian and non-Newtonian flow natures influenced by some factors and conditions [2840]. Some of the factors include nanoparticle volume fraction, nanoparticle size, temperature, base fluid type, surfactants, $\mathrm{pH}$, particle loading, aggregation, nanoclustering, use time, shear rate and stress. For instance, a nanofluid at a low concentration shows Newtonian behavior but at a higher concentration Rheology of a nanofluid is very significant as it identifies its flow nature and affects the pressure drop in flow systems. Thus it is cumbersome for precise determination of the rheological behavior of nanofluids that can be achieved from the relationship between shear rate and shear stress or apparent viscosity. Fig. 1 illustrates rheological behavior of different types of nanofluids showing a wide range of shear rate independent viscosity. Further, Fig. 2 shows shear rate-dependent apparent viscosity of various nanofluids confirming their non-Newtonian flow characteristics. Some of the important rheological outcomes from the literature are narrated in this section. 


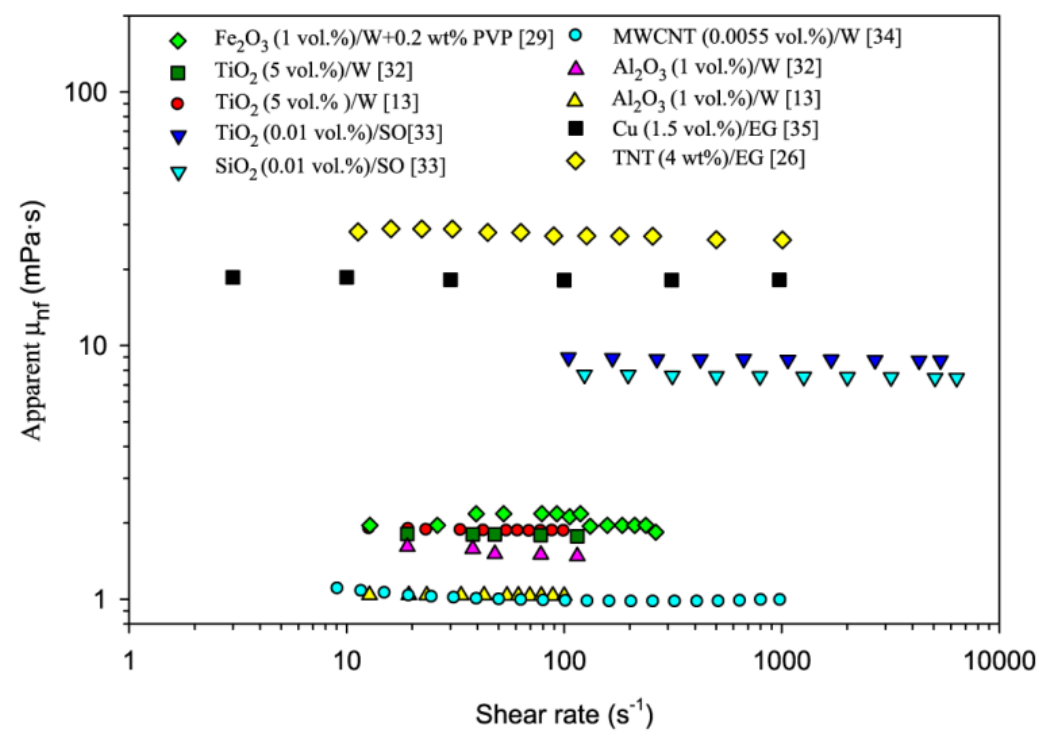

Fig. 1 Literature data on viscosity with shear rate of Newtonian nanofluids at room temperature (Murshed and Estellé [40]).

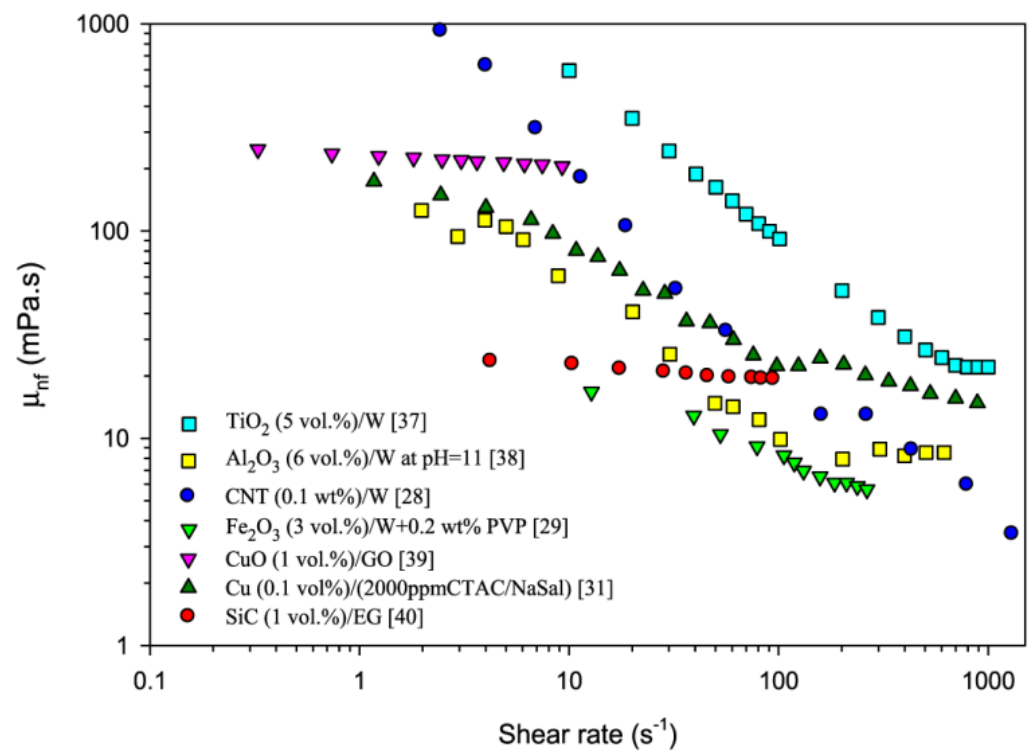

Fig. 2 Literature data on viscosity with shear rate of non-Newtonian nanofluids at room temperature (Murshed and Estellé [40])

Phuoc and Massoudi [29] investigated the effects of shear rates and concentration on viscosity of aqueous $\mathrm{Fe}_{2} \mathrm{O}_{3}$ nanofluids with two different dispersants namely Polyvinylpyrrolidone (PVP) and Polyethylene oxide (PEO). They found that $\mathrm{Fe}_{2} \mathrm{O}_{3}$-water nanofluids with $0.2 \%$ PVP and having nanoparticle volume fraction less than 0.02 behaved as a Newtonian fluid while any further increase in nanoparticle concentration (beyond $2 \mathrm{vol} \%$ ) the nanofluid became non-Newtonian exhibiting shear-thinning behavior. Resiga et al. [36] analyzed rheological properties of highly concentrated transformer oil-based magnetic 


\section{A.K. Patra et al.}

International Journal of Thermofluid Science and Technology (2020), Volume 7, Issue 2, Paper No. 070202

nanofluids. The outcomes of their analysis are that the nanofluids become Newtonian at all concentrations except at the highest concentration of 20.8 vol\%. Further, Chen et al. [41] carried out rheological behavior of titanate nanotubes (TNT)/EG-based nanofluids. They observed that at room temperature and low concentration nanofluids behave as Newtonian, while at higher temperature $\left(>30^{\circ} \mathrm{C}\right)$ and concentration $(>2 \mathrm{wt} \%)$ nanofluids were highly shear thinning.

\section{Experimental Studies on Viscosity Behavior of Nanofluids}

In fact, the dimensionless number associated with heat transfer viz. Nusselt number and Reynolds number are directly related to the viscosity and flow velocity of nanofluids. Further, viscosity has great impact on the mass transfer process as it is related to the diffusion coefficient and transport resistance in both bulk and interfacial regions of nanofluids.

\subsection{Ceramic nanofluids}

Because the ceramic nanoparticles such as $\mathrm{Al}_{2} \mathrm{O}_{3}, \mathrm{CuO}, \mathrm{TiO}_{2}, \mathrm{ZnO}, \mathrm{SiC}, \mathrm{SiO}_{2}$ etc. are chemically more stable in solutions due to their more resistance to oxidation [42], they are better preferred over metals for the synthesis of nanofluids. Furthermore, they have diminutive density and expected particle settling problem [16].

\subsubsection{Aluminum Oxide $\left(\mathrm{Al}_{2} \mathrm{O}_{3}\right)$ nanofluids}

In view of best nanofluid-based coolant, the aluminum oxide $\left(\mathrm{Al}_{2} \mathrm{O}_{3}\right)$ or alumina nanofluid is one of the promising demandable nanofluids which have attracted many researchers to carry out investigation on it. Most relevant studies of on the viscosity of nanofluids reveal that the viscosity augments with increasing particle concentration. Taking into consideration the Newtonian behavior of $\mathrm{Al}_{2} \mathrm{O}_{3}$ nanofluids with a particle diameter of $36 \mathrm{~nm}$ and a volume fraction of 1, 4, 9 and 12\%, Das and Putra [8] declared that the relative viscosities were enhanced by $1.12,1.6,3$ and $5.3 \%$, respectively; and for particle diameter of $47 \mathrm{~nm}$, and volume fractions of $2.1,4.3,8.5$ and $12.2 \%$, the relative viscosity upsurged by $1.1,1.4,2$ and $3.1 \%$. Chandrasekar et al. [9] studied the nanofluids viscosity for $\mathrm{Al}_{2} \mathrm{O}_{3}$ nanoparticles in water. They disclosed that the viscosity rises linearly by upgrading particle concentration up to the concentration of $2 \%$.

There are numerous studies conducted on the effect of temperature on the viscosity of nanofluids. Prasher et al. [20] studied on the effect of temperature for $\mathrm{Al}_{2} \mathrm{O}_{3}$-PG nanofluids for temperature range 30-60 C. Meriläinen et al. [10], Kwek et al. [42] and Jarahnejad et al. [16] conducted the influence of temperature on viscosity of water-based aluminium oxide nanofluids at different temperature ranges $10-50^{\circ} \mathrm{C}, 25^{\circ} \mathrm{C}$ and $20-50^{\circ} \mathrm{C}$ respectively. The above studies explored that the nanofluids viscosity is reduced by increasing the temperature. Tavman et al. [43] conducted experimental investigation of viscosity of suspensions containing nanosized $\mathrm{Al}_{2} \mathrm{O}_{3}$ particles and then they declared that the viscosity of nanofluid augments with increasing the number of nanoparticles and belittles with elevating the temperature.

Nguyen et al. [44] analyzed the effect of particle size on the $\mathrm{Al}_{2} \mathrm{O}_{3}$-water nanofluid and showed that the effect of particle size is significant in high volume fractions. They found 
A.K. Patra et al.

International Journal of Thermofluid Science and Technology (2020), Volume 7, Issue 2, Paper No. 070202

that for volume concentrations less than $4 \%$, the viscosity of $\mathrm{Al}_{2} \mathrm{O}_{3}$-water nanofluid with a particle size of $36 \mathrm{~nm}$ and $47 \mathrm{~nm}$ is approximately identical. They declared that the viscosity of a nanoparticle with a size of $36 \mathrm{~nm}$ is $5 \%$ less than a particle with a size of $47 \mathrm{~nm}$. They also declared that the effect of particle size is more for greater volume fractions (about $7 \%$ and 9\%). Lu and Fan [45], numerically and experimentally examined the viscosity of $\mathrm{Al}_{2} \mathrm{O}_{3}$ water nanofluid and $\mathrm{Al}_{2} \mathrm{O}_{3}$-ethylene glycol in different sizes of nanoparticles, and observed that the viscosity of nanoparticles reduces with augmenting particle diameter. Wen et al. [46] found in examining the viscosity of $\mathrm{Al}_{2} \mathrm{O}_{3}$-water and $\mathrm{Al}_{2} \mathrm{O}_{3}$-ethylene glycol nanofluids that the nanofluids viscosity falls with rising particle diameter. Many researchers investigated the influence of particle size and concentration on the viscosity of $\mathrm{Al}_{2} \mathrm{O}_{3}$ nanofluids. They arrived at the conclusions that high viscosity increments (as high as 137\%) were visualized with smaller particle size and higher concentrations.

On comparison of the results in Murshed et al. [12] with that in Prasher et al. [20], it revealed that the viscosity for water based nanofluids has more influence on nanoparticles than PG based $\mathrm{Al}_{2} \mathrm{O}_{3}$ nanofluids. Lower viscosity increment is achieved for 20:80\% EG/W based $\mathrm{Al}_{2} \mathrm{O}_{3}$ nanofluids than that for $40: 60 \% \mathrm{EG} / \mathrm{W}$ nanofluids (Sundar et al. [47]). In the study of LotfizadehDehkordi et al. [48] experimentally tested the viscosity of $\mathrm{Al}_{2} \mathrm{O}_{3}$ nanofluids at $0.01-1.0 \mathrm{vol} \%$ concentrations. Addition of SDBS surfactant (for stabilization) and sonication in the mixture of alumina nanoparticles with ethylene glycol-water (60:40 mass ratio) base fluid is an unique feature of their study. They observed from their investigation that enhancement of viscosity of nanofluid were $0-23 \%$ with particle concentrations of 0.01-1.0 vol\%. Spherical and fibrous $\mathrm{Al}_{2} \mathrm{O}_{3}$ nanoparticles (5.5 vol\%) were dispersed into ethylene glycol in a temperature range of $20-80{ }^{\circ} \mathrm{C}$ (Kim et al. [49]). With proper sonication for one hour they noticed that the increment of viscosity was higher with fibrous alumina nanofluid. But, at high temperature condition, fibrous nanofluids exhibited less viscosity increment than the spherical one. Duan [50] synthesized water-based $\mathrm{Al}_{2} \mathrm{O}_{3}$ nanofluids contained with $25 \mathrm{~nm}$ size $\mathrm{Al}_{2} \mathrm{O}_{3}$ nanoparticles at $1 \%, 2 \%, 3 \%, 4 \%, 5 \%$ particle volume concentrations and obtained the viscosities as $20 \%$ and $61 \%$ higher than the base fluid at $1 \mathrm{vol} \%$ and $5 \mathrm{vol} \%$, respectively.

\subsubsection{Titanium Oxide $\left(\mathrm{TiO}_{2}\right)$ nanofluids}

Being environmental friendlier nanoparticles titanium dioxide (TiO2) nanoparticles are characterized with high chemical and physical stability. $\mathrm{TiO}_{2}$ nanoparticles are also considered as promising heat transfer medium due to their effective thermophysical properties. Usually, $\mathrm{TiO}_{2}$ nanoparticles appear in three polymorphic phases such as rutile (tetragonal), anatase (tetragonal) and brookite (orthorhombic). Based on their commercial importance rutile and anatase are best suitable for the most researchers in their investigation of viscosity of nanofluids. $\mathrm{TiO}_{2}$ nanofluids were synthesized by the two step method (Leena and Srinivasan [51]). In their synthesis, they dispersed distilled water at 0.04-0.2 wt\% particle concentrations and sonicated the suspensions for duration of $3 \mathrm{~h}$ at $300^{\circ} \mathrm{K}$. The resulting nanofluids were observed to be very stable for more than 6 hours. Hwang et al. [52] developed a well dispersed water-based $\mathrm{TiO}_{2}$ nanofluid wherein they used a high shear 


\section{A.K. Patra et al.}

International Journal of Thermofluid Science and Technology (2020), Volume 7, Issue 2, Paper No. 070202

homogenizer to break particle aggregates and implemented electrostatic repulsion mechanism to stabilize nanoparticles for 1 month without any visual sedimentation. Kumar and Sonawane [53] synthesized aqueous and ethylene glycol-based $\mathrm{TiO}_{2}$ nanofluids with varying duration of ultrasonication and proper dispersion.

The effect of temperature on viscosity of $\mathrm{TiO}_{2}$ nanofluids is investigated by many researchers. The experimental results agree with the fact that viscosity of nanofluids decreases with the increase in temperature. However, the effectively viscosity ratios of nanofluids vary in different reports. Fedele et al. [54], Silambarasan et al. [55] and Jarahnejad et al. [16] declared that the absolute viscosity decreases with the growth of temperature, but the effectively viscosity ratio remain the same with temperature and it is independent of temperature. Teng et al. [56] found that the increment in viscosity of $0.5 \mathrm{wt} \% \mathrm{TiO}_{2}$ - water nanofluids is doubled when temperature increases from 10 to $40^{\circ} C$. However, some other results reveal that temperature effect on relative viscosity is different at different conditions. For instance, the outcome of Yapici et al. [57] conveyed us that temperature has a great effect on the effective viscosity ratio at low shear rate condition but has little effect at high shear rate condition. Das et al. [58] experimentally studied the thermophysical properties of $\mathrm{TiO}_{2}$ nanofluids comprising broader particle concentration range of $0.1-2 \%$ vol\% and at temperatures from 20 to $60^{\circ} \mathrm{C}$. With the addition of surfactants like cetyl trimethyl ammonium bromide (CTAB), acetic acid (AA), oleic acid (OA) and sodium dodecyl sulfate (SDS) they found that the viscosity of the nanofluids increased with particle concentration and decreased with temperature. Azmi et al. [59] studied the heat transfer performance of water-ethylene glycol mixture-based $\mathrm{TiO}_{2}$ nanofluids at temperature $30^{\circ} \mathrm{C}-60^{\circ} \mathrm{C}$ with proper dispersion and suspension at $0.5-1.5 \mathrm{vol} \%$. The viscosity increments were in the range of $4.6-33.3 \%$.

Arulprakasajothi et al. [60] synthesized water-based $\mathrm{TiO}_{2}$ nanofluids with different volume concentrations of $0.1 \%, 0.25 \%, 0.5 \%$ and $0.75 \%$ with dispersion deionized water and ultrasonication. Interestingly, viscosity increments of the nanofluids with $0.1 \%, 0.25 \%, 0.5 \%$, $0.75 \%$ volume concentrations were recorded as $3 \%, 4 \%, 6 \%, 8 \%$ and $13 \%, 13 \%, 14 \%, 15 \%$, respectively for different volume concentrations of $0.1 \%, 0.25 \%, 0.5 \%$ and $0.75 \%$. Sen et al. [61] developed a surface modification method to stabilize the colloidal suspensions of $\mathrm{TiO}_{2}$ particles with particle concentration in the nanofluids as high as $50 \mathrm{wt} \%$. This method is characterized by functionalization of $\mathrm{TiO}_{2}$ nanoparticles by sulfonating the surface of the particles. They found that the viscosity increment was maximum at $50 \mathrm{wt} \%(=21 \mathrm{vol} \%)$ sulfonated nanoparticles $\left(\mathrm{TiO}_{2}-\mathrm{S}\right)$ loading as a 4-fold increment over that of the base fluid. However, the measured viscosity values of nanofluids with sulfonated nanoparticles $\left(\mathrm{TiO}_{2}-\mathrm{S}\right)$ were much less than the previously published results.

Besides particle volume fraction and temperature, another factor such as base fluid can also affect the viscosity of $\mathrm{TiO}_{2}$ nanofluids. Chen et al. [62] examined the viscosity of nanofluids with water and EG as base fluid and containing spherical $(25 \mathrm{~nm})$ and rod-like $(10 \times 100) \mathrm{TiO}_{2}$ nanofluids, respectively. The results revealed that for both water and EG based $\mathrm{TiO}_{2}$ nanofluids, the increment in viscosity by rod-like nanoparticles is much higher than that driven by spherical ones. Particularly, they showed that increment in viscosity of 
A.K. Patra et al.

International Journal of Thermofluid Science and Technology (2020), Volume 7, Issue 2, Paper No. 070202

$\mathrm{TiO}_{2}$ water nanofluids is definitely higher than that with EG as base fluid. Chen et al. [63] showed that EG based TiO2 nanofluid is a Newtonian fluid but the water based $\mathrm{TiO} 2$ nanofluid showed non-Newtonian behavior.

\subsubsection{Copper Oxide ( $\mathrm{CuO})$ nanofluids}

Copper oxide is relevant due to its applications in the area of catalysis, superconductors and ceramics as an important inorganic material. It is fact that the nanoparticles of $\mathrm{CuO}$ exhibit superior catalytic activity, selectivity, peculiar physical and chemical properties than common copper oxide powder.

Namburu et al. [64] examined the viscosity of $\mathrm{CuO}(29 \mathrm{~nm})$ nanofluids with EG/Water $(60: 40)$ as base fluid. They carried out the measurements of the nanofluids in the range of loading from $0 \%$ to $6.12 \%$ and temperature from $-35^{\circ} \mathrm{C}$ to $50^{\circ} \mathrm{C}$. They found that the viscosity of nanofluids upsurge with particle loading enhancement and higher particle loading will yield more noticeable augmentation in viscosity. For instance, the viscosity of nanofluid with $3 \%$ loading is enhanced by $80 \%$, but with $6.12 \%$ loading enhanced four times that of base fluid at $-35^{\circ} C$. Pastoriza-Gallego et al. [65] reported that increased viscosity is dependent on size and poly-dispersity of $\mathrm{CuO}$ with maximum relative viscosity $=1.73$ at $1.7 \mathrm{vol} \%$ in the temperature range $10^{\circ} \mathrm{C}$ to $50^{\circ} \mathrm{C}$ for the viscosity of copper oxide nanofluids.

Prakash et al. [66] investigated that viscosity of the propylene glycol-based nanofluids was lower than ethylene glycol-HPLC water mixture (40/60 v/v ratio)-based $C u O$ nanofluids. In their study, they stirred the suspensions for $2 \mathrm{~h}$ and then added PVP and SLS surfactants and finally sonicated for $2 \mathrm{~h}$ to achieve stable solutions at $25^{\circ} \mathrm{C}$. Table 1 conveys some reports based on the viscosity of $\mathrm{CuO}$ nanofluids.

Table 1 Some reports presented for the viscosity of copper oxide nanofluids.

\begin{tabular}{|c|c|c|c|c|}
\hline Authors & $\begin{array}{l}\text { Temprature } \\
\square \text { \& Concentration } \%\end{array}$ & Rheology & $\begin{array}{l}\text { Base } \\
\text { fluid }\end{array}$ & $\begin{array}{l}\text { Major outcomes with } \\
\text { influence ranks }\end{array}$ \\
\hline Naik et al [67] & $\begin{array}{l}-13 \text { to } 57 \square \& 0.025- \\
1.25 \text { vol\% }\end{array}$ & Newtonian & $\begin{array}{l}\text { PG:Water } \\
(60: 40)\end{array}$ & $\begin{array}{l}\text { Relative viscosity }=1.043 \\
\text { at } 1.2 \mathrm{vol} \%\end{array}$ \\
\hline $\begin{array}{l}\text { Kwak and kim } \\
\text { [68] }\end{array}$ & $\begin{array}{l}25 \square \& 0.01- \\
10 \text { vol\% }\end{array}$ & $\begin{array}{l}\text { Newtonian (up } \\
\text { to } 0.1 \% \text { ) then } \\
\text { sheartthinning }\end{array}$ & EG:Water & $\begin{array}{l}\text { Presence of aggregates, } \\
\text { low shear viscosity } \\
\text { increases with volume } \\
\text { fraction }\end{array}$ \\
\hline $\begin{array}{l}\text { Pastoriza- } \\
\text { Gallego et al. } \\
{[65]}\end{array}$ & $\begin{array}{l}10-50 \square \& 0.16- \\
1.7 \%\end{array}$ & - & Water & $\begin{array}{l}\text { Increased viscosity is } \\
\text { dependent on size and } \\
\text { polydispersity of } \mathrm{CuO} \text {, } \\
\text { maximum relative } \\
\text { viscosity }=1.73 \text { at } 1.7 \\
\text { vol\% and } 10\end{array}$ \\
\hline $\begin{array}{l}\text { Namburu et } \\
\text { al.[64] }\end{array}$ & $\begin{array}{l}-35 \text { to } 50 \square 0- \\
6.12 \text { vol\% }\end{array}$ & Newtonian & $\begin{array}{l}\text { EG:Water } \\
(60: 40)\end{array}$ & $\begin{array}{l}\text { Higher relative viscosity } \\
\text { of } 4.5 \text { at - } \\
30 \square \text { and } 6.12 \text { vol\% }\end{array}$ \\
\hline $\begin{array}{l}\text { Priya et al. } \\
\text { [69] }\end{array}$ & $\begin{array}{l}25-55 \square \& 0.004- \\
0.16 \text { vol\% }\end{array}$ & - & Water & $\begin{array}{l}\text { Maximum relative } \\
\text { viscosity }=1.085 \text { at } 0.16 \\
\text { vol\% and } 55\end{array}$ \\
\hline
\end{tabular}


A.K. Patra et al.

International Journal of Thermofluid Science and Technology (2020), Volume 7, Issue 2, Paper No. 070202

\begin{tabular}{|l|l|l|l|l|}
\hline $\begin{array}{l}\text { Zennifer et } \\
\text { al.[70] }\end{array}$ & $\begin{array}{l}25-140 \square \& 0.25- \\
1 \text { vol\% }\end{array}$ & Newtonian & EG:Water & $\begin{array}{l}\text { Viscosity decrease with } \\
\text { NP loading, relative } \\
\text { viscosity }=0.87 \text { at } 1 \text { vol\% }\end{array}$ \\
\hline
\end{tabular}

\subsubsection{Zinc Oxide $(\mathrm{ZnO})$ nanofluids}

The $\mathrm{ZnO}$ nanoparticles are vital in view of its significant applications using their catalytic, electrical, photochemical, and optoelectronic properties. In addition, thermophysical properties of $\mathrm{ZnO}$ nanofluids were investigated by many researchers. Recently, investigations revealed that dispersion of $\mathrm{ZnO}$ nanoparticles in water without addition of surfactants was not easily carried out [71,72]. The reason behind such difficulties is that the isoelectric point of $\mathrm{ZnO}$ nanoparticles is around $\mathrm{pH}$ : 7 due to which the charges of $\mathrm{ZnO}$ nanoparticles in the suspension are insufficient to resist agglomeration without $\mathrm{pH}$ adjustment or surfactant addition (Suganthi and Rajan [71]). Further, the $\mathrm{ZnO}$ nanofluids become stable when the $\mathrm{ZnO}$ nanoparticles are dispersed into polar organic solvents such as ethylene glycol or propylene glycol by ultrasonic treatment (Witharana et al. [73]).

A mixture of ethylene glycol-water (50:50 vol\%)-based $\mathrm{ZnO}$ nanofluids was synthesized by Cabaleiro et al. [74]. They implemented the sequential method of Suganthi and Rajan [71] for the synthesis of nanofluids where initially the $\mathrm{ZnO}$ nanoparticles were dispersed into ethylene glycol and sonicated in an ultrasonic bath of $90 \mathrm{~W}$ for $10 \mathrm{~min}$. The suspension was then diluted by adding requisite amount of water for obtaining $1.0 \%, 2.5 \%$, and 5\% mass concentrations. This method prevents direct contact of $\mathrm{ZnO}$ nanoparticles with water. They sonicated the final dispersions at $20 \mathrm{kHz}$ and maximum power of $130 \mathrm{~W}$ with optimum conditions $60 \mathrm{~min}$ effective sonication at $120 \mathrm{~W}$ and ultrasound irradiation. An enhancement of viscosity was noticed with particle concentration.

Suganthi and Rajan [71] examined the influence of nanoparticles-liquid interactions on the viscosity of mixture of propylene glycol-water-based $\mathrm{ZnO}$ nanofluids. They added $2 \mathrm{vol} \%$ of spherical $\mathrm{ZnO}$ nanofluids in the dispersion of propylene glycol-water (50-50 vol\%) suspension which was treated by an ultrasonicator of $130 \mathrm{~W}$ for $2 \mathrm{~h}$ with no surfactant addition. The results of the work convey that the viscosity was reduced by $11.4 \%$ at $28{ }^{\circ} \mathrm{C}$. Suganthi et al. [75] investigated the heat transfer performance of the mixture of propylene glycol-waterbased $\mathrm{ZnO}$ nanofluids. They synthesized the suspension of $\mathrm{ZnO}$ propylene glycol with 4 vol\% particle concentration. The suspension was diluted to $0.5 \mathrm{vol} \%, 1.0 \mathrm{vol} \%, 1.5 \mathrm{vol} \%$, and 2.0 vol\% concentrations by adding water and then sonicated using an ultrasonication probe. It was observed that $10 \%$ reduction in viscosity was obtained at 2 vol\% particle concentration. In addition, higher solar heat absorption capability was visualized by the incorporation of $\mathrm{ZnO}$ nanoparticles attributing to reduced viscosity of propylene glycol-water-based $\mathrm{ZnO}$ nanofluids.

\subsubsection{Silicon dioxide $\left(\mathrm{SiO}_{2}\right)$ nanofluids}

Tavman and Turgut [76] examined the viscosity of water based nanofluids containing $\mathrm{SiO}_{2}$ nanoparticles. They found that the effective viscosities become up due to the growth of particle loading and reduce with rise in temperature. They further added 1.85 vol. $\% \mathrm{SiO}_{2}$ nanoparticles and observed that viscosity of fluid was increased by $90 \%$. Azmi et al. [59] disclosed in his study that viscosity ratio augmented from 1.05 to 1.49 due to increase in the 
A.K. Patra et al.

International Journal of Thermofluid Science and Technology (2020), Volume 7, Issue 2, Paper No. 070202

volume fraction from 0.5 to $4 \%$. However, there is also a larger enhancement in viscosity of $\mathrm{SiO}_{2}$ nanofluids in Masuda et al.'s report [77]. They also disclosed that the viscosity was increased up to three times of base water with addition of $2.4 \mathrm{vol} . \% \mathrm{SiO}_{2}$ nanoparticles.

Kulkarni et al. [78] developed EG/W (60: 40wt.\%) based $\mathrm{SiO}_{2}$ nanofluids and measured at different particle loadings $(2 \%$ to10\%), sizes $(20 \mathrm{~nm}, 50 \mathrm{~nm}$ and $100 \mathrm{~nm})$ and temperatures $\left(-35^{\circ} \mathrm{C}\right.$ to $\left.50^{\circ} \mathrm{C}\right)$. They found that there is upgradation of viscosity of nanofluids with increase in particle content while it decreases as the particle size or temperature gets enhanced. The effect of particle loading, temperature and base fluid type on the viscosity of $\mathrm{SiO}_{2}$ nanofluids was examined by Jamshidi et al. [79]. The outcome of their investigation is that the viscosity of $\mathrm{SiO}_{2}$ nanofluids augmented with the particle loading and diminished with the growth in temperature. In fact, the viscosity of $\mathrm{SiO}_{2}$ nanofluids with water as base fluid was higher than those with ethylene glycol or transformer oil. As a consequence, lower viscosity base fluid could lead to higher enhancement in viscosity of $\mathrm{SiO}_{2}$ nanofluids.

\subsubsection{Silicon Carbide $(\mathrm{SiC})$ nanofluids}

The measurement of the viscosity of $\mathrm{SiC}$-water nanofluids by $\mathrm{Yu}$ et al. [80] revealed that the relative viscosity is about 1.8 to 2.0 times the viscosity of base water at 3.7 vol.\% particle loading with temperature rise from 25 to $70^{\circ} \mathrm{C}$ (viscosity increment is relatively low). A similar enhancement in the viscosity of $\mathrm{SiC}$-water nanofluids was observed by Lee et al. [81]. In this case they found that the viscosity was doubled with the addition of 3 vol.\% $\mathrm{SiC}$ nanoparticles. They also further found that the relative viscosity of $\mathrm{SiC}$-water nanofluids at every concentration diminished with rise in temperature.

\subsection{Magnetic nanofluids}

The mixture of different magnetic nanoparticles such as metals (ferromagnetic materials) $\mathrm{Co}$ and $\mathrm{Fe}$, metal oxides (ferrimagnetic materials) $\mathrm{Fe}_{3} \mathrm{O}_{4}, \mathrm{Fe}_{2} \mathrm{O}_{3}, \mathrm{CoFe}_{2} \mathrm{O}_{4}$ with several base fluids are referred as magnetic nanofluids [82-84]. Especially the magneto nanofluids are significant in applications like optical modulators, magneto-optical wavelength filters, tunable optical fibre filters and optical switches. Magnetic nanoparticles are especially useful in biomedicine, sink float separation, cancer therapy, aerospace etc. Specific biomedical applications involving nanofluids include hyperthermia, magnetic cell separation, drug delivery and contrast enhancement in magnetic resonance imaging [85-97]. Because the magnetic nanofluids can be controlled and manipulated by an external magnetic field, researchers consider such fluids as promising fluids in heat transfer applications [98-99]. Sundar et al. [47] examined the viscosity of nanofluids with water as base fluid and $\mathrm{Fe}_{3} \mathrm{O}_{4}$ as nanoparticles. Nanofluids were synthesized through proper dispersion, CTAB surfactant addition and sonication. They found the results later that for $0.2 \mathrm{vol} \%$ concentration, the viscosity upsurged by $106.3 \%$ at $20^{\circ} \mathrm{C}$ and $209 \%$ at $60^{\circ} \mathrm{C}$.

\subsection{Metallic nanofluids}

Singh et al. [100] obtained the dispersion of $C u$ nanoparticles at different concentrations into synthetic oil. Well-Defined single crystal nanoparticles at $50-100 \mathrm{~nm}$ size range were developed after sonication of $4 \mathrm{hrs}$ at $120{ }^{\circ} \mathrm{C}$. They found that the viscosity augmented with 


\section{A.K. Patra et al.}

International Journal of Thermofluid Science and Technology (2020), Volume 7, Issue 2, Paper No. 070202

the increase of particle loading. Diethylene glycol-based $C u$ nanofluids were prepared through the dispersion of diethylene glycol and $\mathrm{Cu}$ nanoparticles and proper sonication (Nikkam et al. [101]). The lower increments of viscosity of nanofluids were accomplished. Aqueous-based bimetallic $\mathrm{Cu} / \mathrm{Pd}$ nanofluids with various molar ratios were developed by Jaiswal et al. [102]. Stable suspensions were achieved through PVP. They observed that addition of $\mathrm{Cu}$ nanoparticles led to small increments of viscosity of nanofluids. Because of high cost, few investigators have carried out their studies on gold and silver nanofluids. Chen and Wen [103] prepared an ultrasonic-aided single-step method for synthesizing gold nanofluids. The addition of a very low concentration of $A u$ nanoparticles in water resulted in lower viscosity of nanofluids.

\subsection{Diamond nanofluids}

Diamond nanofluids have great advantages over other nanofluids due to the highest thermal conductivity of diamond (Diamond is characterized with strong carbon-carbon covalent bonding and low phonon scattering). For instance, thermal conductivity is typically over $2200 \mathrm{~W} /(\mathrm{mK})$ and as high as $3320 \mathrm{~W} /(\mathrm{mK})$ of isotropically pure monocrystalline synthetic diamond [104]. In order to suppress aggregation and improve the dispersion behavior of nanofluids, three different methods such as use of surfactants, $\mathrm{pH}$ control, and ultrasonic agitation have been implemented. To examine the nanoparticle shape and other significant characteristics transmission electron microscopy (TEM) has been usually applied before being the nanoparticles dispersed into the base fluid. In the analysis of diamond nanofluids, zeta potential is the best suitable method to evaluate nanofluid stability and dispersion. Sundar et al. [105] took nano diamond soot with strong sulfuric acid and nitric acid solution in their synthesis. The carbon impurities were removed by acid treatment and the nanodiamond particles were functionalized by forming carboxyl groups on the nanoparticle surfaces. The synthesized nanoparticles were dispersed into the base fluid of ethylene glycol water mixtures at varying mixing ratios. The suspensions were subject to sonication for $2 \mathrm{~h}$ in an ultrasonic bath. Zeta potential was applied for the stability of the synthesized nanofluids. Their outcomes include that the viscosity values were also enhanced by $274 \%, 173 \%$ and $192 \%$, respectively, at $1.0 \mathrm{vol} \%$ concentration and at $60^{\circ} \mathrm{C}$. The same acid treatment procedure was carried out on diamond nanoparticles by Sundar et al. [47]. In the synthesis procedure carboxylated nanodiamond particles were dispersed into distilled water at varying concentrations and then the solution was sonicated in an ultrasonic bath for $2 \mathrm{~h}$. in view of long term stability along with good dispersion, zeta potential was adopted and the $\mathrm{pH}$ of the solution was adjusted by addition of $\mathrm{NaOH}$. Under these conditions the viscosity was highly increased by $179 \%$. Such very high viscosity increments implicate insufficient thermal properties of nanodiamond nanofluids. Kalidasan and Kanna [106] studied the natural convection on an open square cavity containing diagonally placed heaters and adiabatic square block and filled with hybrid nanofluid of nanodiamond - cobalt oxide/water. The influence of ash content on thermophysical properties of ethylene glycol based graphite/diamonds mixture nanofluids was analyzed by Yla et al. [107]. Further, Puzir et al. [108] explored the effect of silver ions electrolytically introduced into colloidal nanodiamond solution on its viscosity and thermal conductivity.

Augmentation in viscosity is the result due to addition of diamond nanoparticles to a base fluid. Such result is not desirable as it yields energy loss. This enhancement may be influenced by nanodiamond concentration and particle size. An enhancement of $20 \%$ in 
A.K. Patra et al.

International Journal of Thermofluid Science and Technology (2020), Volume 7, Issue 2, Paper No. 070202

viscosity at higher-concentration nanofluid samples was obtained by Ghazvini et al. [109]. Increasing density of a nanofluid did not yield significant increase in kinematic viscosity of the diamond nanofluid (Taha-Tijerina et al. [110]). However, up to a $12 \%$ increase in dynamic viscosity was obtained in a nanodiamond volume fraction of $0.03 \%$ at $100^{\circ} C$. Such increment was not a large rise compared to other studies, for instance the one by Gudson et al. [111] where more than a $30 \%$ rise in dynamic viscosity has been declared for silver nanofluids. Further, Tyler's work [112] reported 7, 76 and 140\% increase in viscosity for concentrations of 1, 2 and $3 \mathrm{wt} \%$ using midel oil as the base fluid attributing to their largesized nanoparticles (around $450 \mathrm{~nm}$ on average) compared to other nanodiamond fluids. Sundar et al. [47] found that the viscosity of the diamond nanofluids upsurges with more particle loading and belittles with rising temperature. The highest nanodiamond fluid viscosity rise was reported as $79 \%$ at $60^{\circ} \mathrm{C}$. They compared their viscosity results with theoretical models for two-phase suspensions and validated the results. Generally, there is no consistency between viscosity increases in diamond nanofluids. The base fluid properties and, above all, interactions between the base fluid and diamond nanoparticles have the most influence on the viscosity.

When nanodiamond particles are added to dielectric fluids, such heat transfer nanofluids characterized by high thermal conductivity and minimal electrical conductivity can be appropriate for electronic cooling applications [113]. The thermal behavior of the cooling fluid in the fin-type heat sink of a central processing unit (CPU) in computers was modeled and compared it with experimental results (Naphon et al. [114]). Their results led to a non-uniform temperature distribution in the heat sink, which could be a problem for the electronic devices. However, those results can be guidelines for achieving a novel cooling system designed with enhanced thermal performance. Experimental examinations and simulations on diamond nanofluid thermal properties and heat transfer characteristics associated with cooling desktop PCs was carried out by Gunnasegaran et al. [115]. Three different nanoparticles including nanodiamond in transformer oil were examined by Choi et al. [116]. They considered them as a new type of coolant for automotive heat management. Ma et al. [117] reported that diamond nanofluid-based oscillating heat pipes can extract heat fluxes exceeding $10 \mathrm{MW} / \mathrm{m}^{2}$ which they considered as the future generation of cooling devices in electric systems. Diamond nanofluids can be applied in wheel grinding and the associated tribological behavior in grinding of cast iron under wet and dry conditions (Shen et al. [118]). They used a minimum amount of lubrication for potential applications in engine operation and compared the results with those of water. They found that diamond nanofluid grinding could significantly reduce the grinding temperature and grinding forces, increase surface roughness, and prevent work piece burning compared to dry grinding.

\subsection{Carbon nanotubes nanofluids}

In 1991, Sumio Lijima [119] discovered carbon nanotubes. Because of excellent properties carbon nanotubes have been attracted by diversified sectors [120-122]. In the beginning, multi walled carbon nanotubes (MWCNTs) in carbon soot were produced by an arc discharge method (Lijima [123] in 1991. Two years later, he observed the single walled carbon nanotubes (SWCNTs). Dispersion of CNTs in the base fluid is challenging due to the tendency of nanotubes to agglomerate. Stable CNT nanofluids can be synthesized physically by ultrasonication, high shear mixing, ball milling, and/or chemically by functionalization through altering the surface chemistry of the nanotubes covalently, and the addition of 


\section{A.K. Patra et al.}

International Journal of Thermofluid Science and Technology (2020), Volume 7, Issue 2, Paper No. 070202

surfactants which adsorb onto the nanotubes surfaces non-covalently. Functionalization over the other surfactant free method provides good fluidity, long-term stability, significant heat transfer (Aravind et al. [124]). Functionalized CNTs are used as advanced heat transfer fluids in thermal energy/heat exchange engineering systems. They evaluated the viscosity of four groups of CNTs nanofluids at a very low volume fraction of $0.005 \%$ and $0.03 \%$ with water and EG as base fluids, respectively. The results conveyed that the relative viscosity of CNTs nanofluids is not sensitive to the base fluid type but influenced by the temperature since the relative viscosity at $70^{\circ} \mathrm{C}$ was higher than that at $30^{\circ} \mathrm{C}$. A functionalization method to stabilize CNT nanofluids was developed by Esumi et al. [125]. In this method, $1 \mathrm{~g}$ CNT was dispersed and treated in a mixture of concentrated nitric acid and sulfuric acid (1:3 volume ratio) for 30 mins and refluxed at $140^{\circ} \mathrm{C}$. Having washed with deionized water till $p H=7$ nanotubes were dried at $100^{\circ} \mathrm{C}$ in vacuum and then $0.01 \mathrm{~g}$ of dried samples were suspended in $30 \mathrm{ml}$ of different liquids. Ultrasonication was applied to the latest suspensions about $4 \mathrm{hr}$. The resultant nanotubes were well dispersed into individual fibers in base fluids. This established method has been applied by many researchers in their experiments ([126-129]). The colloidal stability of functionalized MWCNT-based nanofluids was examined by Lamas et al. [130] where he suggested that functionalization of CNTs helps greatly in the formation of highly stable nanofluids. The thermophysical properties of water-based SWCNTs nanofluids with varying nanotubes concentrations in the range of $0.1-1 \mathrm{wt} \%$ and at a temperature range of $10-100^{\circ} \mathrm{C}$ was studied by Xing et al. [131]. They declared from their study that viscosity and density of nanofluids incremented with the rise in nanotubes concentration. An increased viscosity of $35.9 \%$ at $1 \mathrm{wt} \%$ nanotubes loading at $60^{\circ} \mathrm{C}$ was reported. Ding et al. [28] used a variety of surfactants in stabilizing CNT-water nanofluids. Surfactants such as sodium laurate (SL), sodium dodecyl benzene sulfonated (SDBS) and Gum Arabic (GA) can stabilize CNTs in the suspension for over 1 month without any visual sedimentation. They reported linear shear thinning behavior of their nanofluids whereas their base showed nonlinear shear thinning nature. Sabiha et al. [132] prepared a water-based SWCNTs nanofluid with addition of SDS to stabilize the suspensions and with sonication for $1 \mathrm{~h}$. Increment of viscosity by $82.01 \%$ was the expected result. Singh et al. [133] investigated the viscosity of CNT-EG nanofluids. Before CNTs being dispersed into ethylene glycol and sonicated for $1.5 \mathrm{~h}$, those were functionalized by acid treatment. The outcome of the study was that viscosity increased with CNT concentration but exponentially decayed with temperature.

Chen et al. [134] examined the viscosity of CNTs-water nanofluids and found that increment of temperature from 6 to $65^{\circ} \mathrm{C}$ can greatly reduce the viscosity of nanofluids but has little effect on the relative viscosity. With the addition of very slight amount of CNTs, such as $0.2 \mathrm{vol} . \%$ can unexpectedly reduce the viscosity of base fluid. This implicates that the nanofluid has a lower viscosity compared to the base fluid. Phuoc et al. [135] found that the viscosity of water based nanofluids containing $0.5 \mathrm{wt} \%$ CNTs were lower than distilled water. This is due to the lubricating effect of nanoparticles. Besides the particle loading and temperature effect, the shear rate effect is more extensively studied. CNTs nanofluids exhibit non-Newton behavior. Ko et al. [136] synthesized two types of water based CNTs nanofluids by acid treatment and by surfactant treatment, respectively. Their results showed that both kinds are non-Newton fluids and exhibit noticeable shear thinning behavior at all kind of concentrations. The viscosities of CNTs nanofluids prepared by both acid and surfactant treatment (TCNT) are lower than that of pristine CNTs nanofluids (PCNT). Further, the 
A.K. Patra et al.

International Journal of Thermofluid Science and Technology (2020), Volume 7, Issue 2, Paper No. 070202

viscosities of CNTs nanofluids developed by the acid treatment are obviously lower than the ones developed with surfactant. Garg et al. [137] measured the viscosity of CNTs nanofluids prepared by different period of ultrasonication. They disclosed that CNT nanofluids showed a typical non-Newtonian behavior in accordance with the Power Law viscosity model. The initial sonication will induce growth in viscosity of nanofluids. The rationally behind is that the clusters of CNT bundles by sonication improve the dispersion. However, the longer time sonication breaks the CNTs into shorter ones which in turn destroy the networking of CNTs and weaken the dispersion situation there by decreasing in viscosity. The impact of particle loading and temperature on the viscosity of CNT nanofluids was reported by Halelfadl et al. [138]. The results revealed that the nanofluids exhibited Newtonian behavior at lower particle loading but a shear thinning behavior at higher loading. The viscosity greatly increases at high particle loading owing to the aggregates of CNTs. Temperature has impact on the absolute viscosity but has little effect on the relative viscosity of nanofluids at high shear rate. Many others [139-140] discussed in the related areas. Ding et al. [28] analyzed the viscosity of CNT water nanofluids under different particle loading, temperature and $\mathrm{pH}$ values. In their study, they observed that the viscosity of water-based nanofluids of multi-walled carbon nanotubes as a ratio of the shear rates in different volume fractions and temperatures. Their report reveals that at all shear rates, the viscosity of nanofluid enhances with rise in the volume fraction and reduces with incrementing the temperature. They also revealed the Newtonian behavior for a nanofluid without surfactant. With adding Arabic gum as a surfactant, they observed a thin shear behavior for lower shear rates and a thick shear behavior for shear rates over $200 \mathrm{~s}^{-1}$. The experimental results focused in Fig. 3 represents that the viscosity of CNT nanofluids upsurge with the rise of particle content and fall in temperature. It is also shown in Fig. 4 that how the viscosity varies with temperature for nanofluids made with water and ethylene glycol as base fluids and with multi walled carbon nanotubes as nanoparticles. A shear thinning behavior in nanofluids was noticed. Such characteristic is applied to tubular geometry because the lower viscosity and better lubrication appear at the wall region. They also showed that the viscosity of pure gum Arabic fluid is much lower than that of the CNT nanofluid. They also eliminated the doubt that the gum Arabic dispersant produce the shear thinning behavior since the viscosity of pure gum Arabic fluid is much lower than that of the CNT nanofluid (Fig.5).

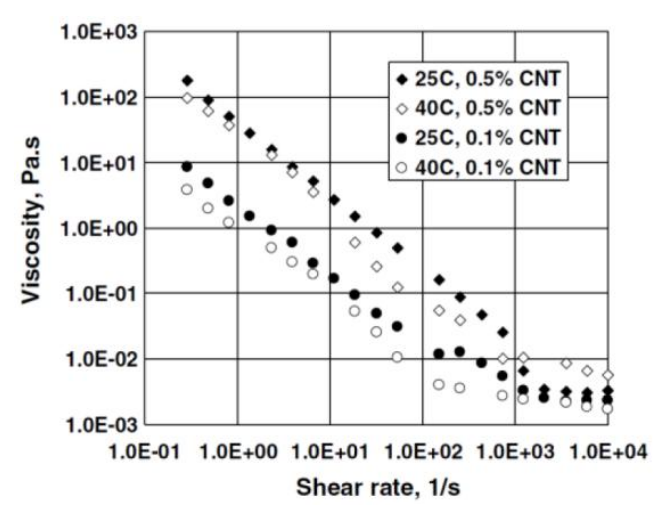

Fig. 3 Viscosity as a function of shear rate for CNT nanofluids (Ding et al. [28])



Fig. 5 Viscosity as a function of shear rate for gum Arabic solutions: $0.25 \%$ (Ding et al. [28]) 

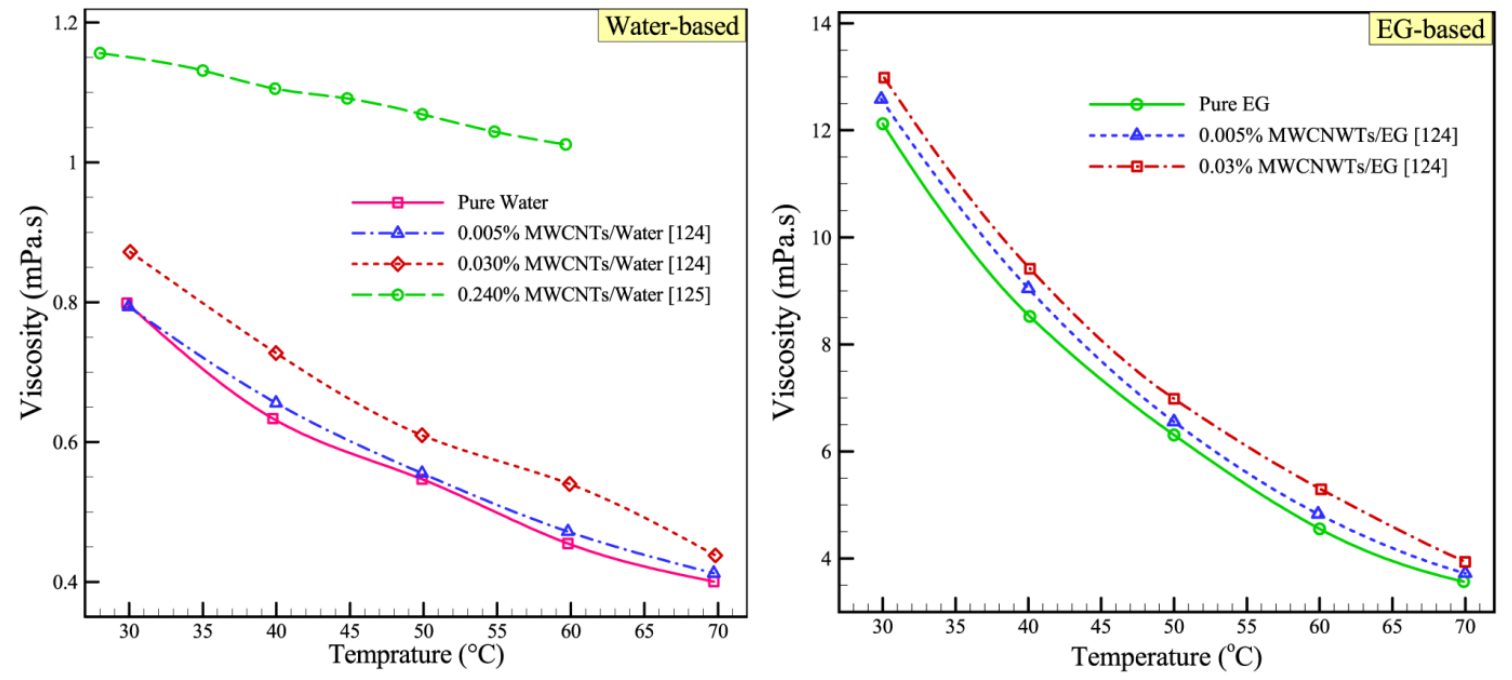

Fig. 4 Viscosity changes with temperature for Water-based and EG-based nanofluids containing MWCNTs (Khodadadi et al. [139])

In another study, Yang et al. [141] used polyisobutylene succinimide surfactant for the production of a nanofluid of multi-walled carbon nanotubes in oil. They also used the ultrasonic methods for homogenization and stabilization. They showed that this surfactant well controlled the viscosity of nanofluids, especially at low shear rates. The Newtonian behavior is observed for very low volume fractions of carbon nanotubes while the nonNewtonian behavior is observed at low shear rates. Kinloch et al. [142] studied the rheological behavior of water nanofluid-oxidized carbon nanotube. He observed a thin shear behavior for all nanofluids volume fractions. They also observed augmented viscosity by increasing the volume fraction. Vakili-Nezhaad and Dorany [143] determined the suspension of single-walled carbon nanotubes in lubricating oil at temperature ranging from $25^{\circ} \mathrm{C}$ to $100^{\circ} \mathrm{C}$ and obtained that increase of $33 \%$ viscosity of this nanofluid in a $0.2 \%$ volume fraction. Ruan and Jacobi [144] examined the rheological properties of nanofluid produced by considering multi-walled carbon nanotubes as nanoparticles and ethylene glycol with a volume fraction of 0.5 as base fluids with ultrasonic effects. They disclosed that at a constant shear rate, the viscosity initially increased and then decreased, with rising ultrasonic time. Table 2 conveys some studies conducted on nanofluids made with different carbon nanotubes.

Table 2 Some studies on nanofluids made with carbon nanotubes.

\begin{tabular}{|c|c|c|c|}
\hline Authors & CNTs/base fluid & Rheology & Key results/remarks with influence ranks \\
\hline $\begin{array}{l}\text { Yang et al. } \\
{[145]}\end{array}$ & MWCNTs/Oil & $\begin{array}{l}\text { Newtonian } \\
\text { and shear } \\
\text { thinning }\end{array}$ & $\begin{array}{l}\text { At } \varphi=0.34 \text { vol } \% \tau=10 \mathrm{~Pa}: \mu e f f=1570 \\
\tau=50 \mathrm{~Pa}: \mu e f f=30.20\end{array}$ \\
\hline $\begin{array}{l}\text { Garg et } \\
\text { al.[146] }\end{array}$ & MWCNTs/Water & $\begin{array}{l}\text { Non- } \\
\text { Newtonian } \\
\text { shear thinning }\end{array}$ & $\begin{array}{l}\text { A number of mechanisms related to boundary layer } \\
\text { thickness ,micro-convective effects,particle } \\
\text { rearrangement, effect due to viscocity }\end{array}$ \\
\hline $\begin{array}{l}\text { Chen et } \\
\text { al. }[41,128]\end{array}$ & MWCNTs/Water & - & $\begin{array}{l}\text { At } \varphi<0.4 v o l \% T<55 \square: \mu e f f<1(\text { decreasing }) \\
\mathrm{T}=55 \square: \mu e f f>1(\text { increasing })\end{array}$ \\
\hline
\end{tabular}


A.K. Patra et al.

International Journal of Thermofluid Science and Technology (2020), Volume 7, Issue 2, Paper No. 070202

\begin{tabular}{|c|c|c|c|}
\hline $\begin{array}{l}\text { Xie and } \\
\text { Chen } \\
{[147]}\end{array}$ & $\begin{array}{l}\text { MWCNTs/Silicon } \\
\text { oil }\end{array}$ & Newtonian & At $\varphi=0.54 w t \%: \mu e f f<1($ decreasing $)$ \\
\hline $\begin{array}{l}\text { Phuoc et } \\
\text { al.[135] }\end{array}$ & MWCNTs/Water & $\begin{array}{l}\text { Non- } \\
\text { Newtonian }\end{array}$ & At $\varphi=0.5 w t \%: \mu e f f=0.8($ decreasing $)$ \\
\hline $\begin{array}{l}\text { Harish et } \\
\text { al.[148] }\end{array}$ & SWCNTs/Water & - & At $\varphi=0.3$ vol $\%: \mu e f f=1.3$ \\
\hline $\begin{array}{l}\text { Estelle et } \\
\text { al.[149] }\end{array}$ & MWCNTs/Water & $\begin{array}{l}\text { Newtonian } \\
\text { and shear } \\
\text { thinning }\end{array}$ & $\begin{array}{c}\text { At } \varphi=0.55 \text { vol } \% \mu e f f=5.2 \text { wit } \square S D B S \\
\mu e f f=1.5 \text { wit } \square \text { lignin }\end{array}$ \\
\hline $\begin{array}{l}\text { Sadri et } \\
\text { al.[150] }\end{array}$ & MWCNTs/Water & $\begin{array}{l}\text { Newtonian } \\
\text { and shear } \\
\text { thinning }\end{array}$ & $\begin{array}{l}\text { Nanofluids viscosity increased up to } 7 \text { min of } \\
\text { sonication and then decreased with more rise in } \\
\text { sonication time }\end{array}$ \\
\hline $\begin{array}{l}\text { Maillaud } \\
\text { et al.[151] }\end{array}$ & CNTs/Water & Shear thinning & $\begin{array}{l}\text { Nanofluids viscosity augmented with TX100 and CNT } \\
\text { loading }\end{array}$ \\
\hline
\end{tabular}

\subsection{Other nanofluids}

\section{$\mathrm{Fe}_{2} \mathrm{O}_{3}$ nanofluids}

There are some factors including particle loading, temperature, surfactant, shear rate and shear time have impacts on viscosity of $\mathrm{Fe}_{2} \mathrm{O}_{3}$ nanofluids. Abareshi et al. [152] synthesized $\alpha-\mathrm{Fe}_{2} \mathrm{O}_{3}-$ glycerol nanofluids and revealed that the viscosity shows an ascending trend with increase of particle volume fraction and belittles with the growth of temperature. The magnetic $\alpha-\mathrm{Fe}_{2} \mathrm{O}_{3}-$ glycerol nanofluids exhibit non-Newtonian behavior where the shear viscosity is greatly affected by temperature. As a unique property, they found that the relative viscosity is lower than the prediction of conventional models. The viscosity of ammonia water based $\mathrm{Fe}_{2} \mathrm{O}_{3}$ nanofluids with SDBS as dispersant was studied by Yang et al. [145]. They observed that the effect of surfactant on the viscosity is greater in comparison to $\mathrm{Fe}_{2} \mathrm{O}_{3}$ nanoparticles at low concentrations. They also observed that the viscosity will decrease due to the addition of very little amount of $\mathrm{Fe}_{2} \mathrm{O}_{3}$ nanoparticles in ammonia water with higher concentration of SDBS. The root cause behind this decrement in viscosity is that the adsorption of SDBS on the particle surface will reduce the "free surfactant" in the fluid. Pastoriza-Gallego et al. [65] analyzed the viscosity of EG based $\mathrm{Fe}_{2} \mathrm{O}_{3}$ nanofluid at room temperature. In their investigation, the nanoparticles are composed of hematite of hexagonal scalenohedral-shaped ones. According to their declaration for a given shear rate, $\mathrm{Fe}_{2} \mathrm{O}_{3}-E G$ nanofluids showed non-Newtonian behavior and the shear thinning effect is related to the time until arrives at a final status of exhibiting viscoelasticity.

\section{$\mathrm{Al}_{2} \mathrm{O}_{3}$ - Isopropanol nanofluid}

Initially, the original dried out nanoparticles were characterized by SEM (scanning electron microscopy), TEM (transmission electron microscopy) and EDS (electron diffraction spectra). Here, nanoparticles are close to spherical in shape. The TEM images were used to measure the size of dry nanoparticles and reported that the log-normal distribution for dry 


\section{A.K. Patra et al.}

International Journal of Thermofluid Science and Technology (2020), Volume 7, Issue 2, Paper No. 070202

nanoparticles corresponds to $8 \mathrm{~nm}$. Further, distribution of nanoparticles size in solution obtained by DLS is also lognormal, but its peak corresponds to $70 \mathrm{~nm}$ (mean size is $75 \mathrm{~nm}$ ). Moreover, the mean size of nanoparticles obtained by ST (spectral turbidimetry) method [153-155] was $82 \mathrm{~nm}$. The viscosity of nanofluids obtained from theory is in good agreement with obtained experimental results at low concentrations of nanoparticles (up to 0.992 mass \%). However, at the higher concentrations of nanoparticles in the solution the deviations are quite big (up to $0.53 \mathrm{~m} \mathrm{~Pa} \mathrm{s)} \mathrm{[Fig.} \mathrm{6].}$

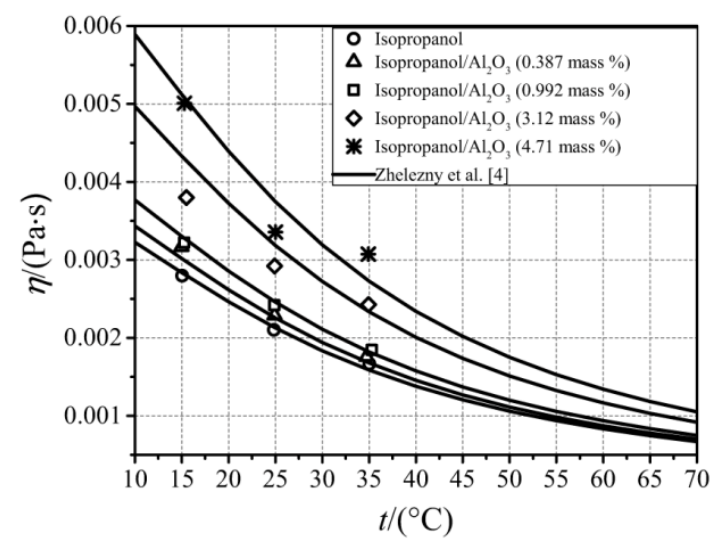

Fig. 6 Viscosity as a function of the temperature and mass fraction of nanoparticles

The experimental study on the viscosity of nanofluids revealed that at 4.71 mass $\%$ of nanoparticles the temperature dependence of the viscosity is non-linear. It is important to mention here that the non-linear temperature dependence of viscosity was previously found in Murshed et al. [33] and indicate structural changes in isopropanol/ $\mathrm{Al}_{2} \mathrm{O}_{3}$ nanofluid at the certain concentrations and temperatures. Moreover, the temperature dependence of the viscosity at 4.71 mass\% shows a non linear behavior. Furthermore, isopropanol/ $\mathrm{Al}_{2} \mathrm{O}_{3}$ nanofluids obey Newton's law of viscosity (Newtonian liquid) within the entire range of parameters and with addition of $\mathrm{Al}_{2} \mathrm{O}_{3}$ nanoparticles to isopropanol increase the viscosity. As far as the hydrodynamic behavior of the nanofluid is concerned, the higher viscosity of the nanofluid, due to the enhancement of the nanoparticles mass fraction, leads to a rise in pressure drop, both in laminar and turbulent regimes [Fig. 7].

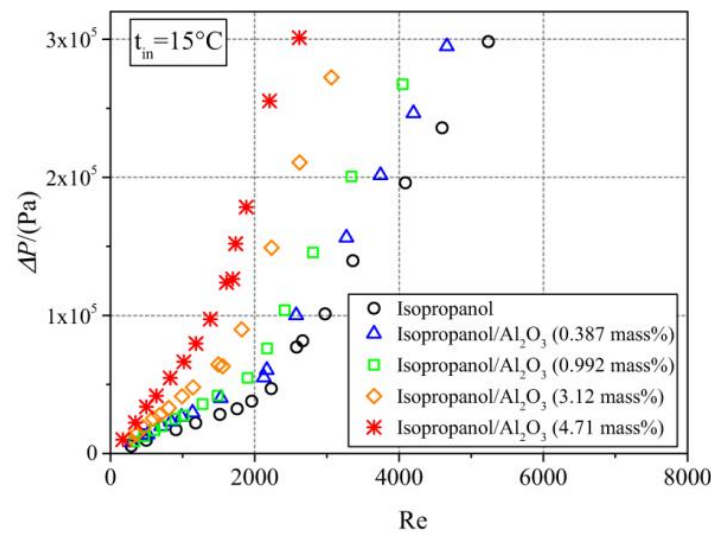

(a)



(b) 


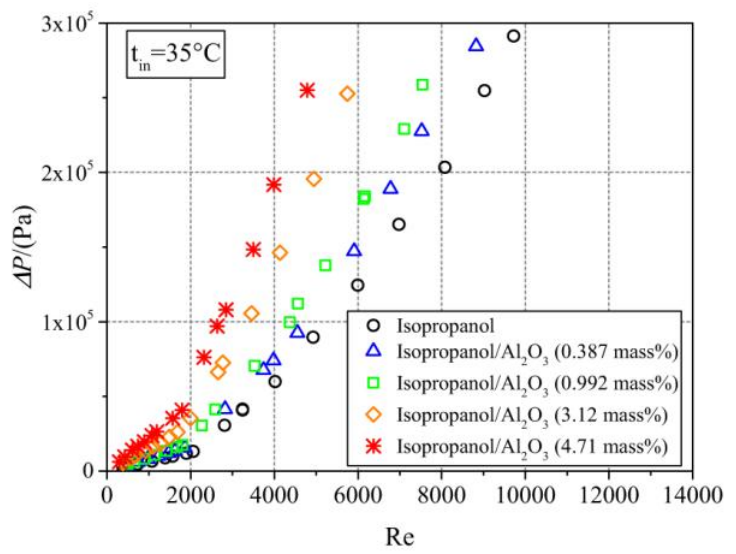

(c)

Fig. 7 Pressure drop as function of Re number and mass fraction of nanoparticles for: (a) $t_{\text {in }}=15^{\circ} \mathrm{C}$ (b) $t_{\text {in }}=25^{0} \mathrm{C}$ (c) $t_{\text {in }}=35^{\circ} \mathrm{C}$ (Nikulin et al. [156])

\section{$\mathrm{CaCO}_{3}$ nanofluid}

The $\mathrm{CaCO}_{3}$ - water nanofluids possessing $\mathrm{CaCO}_{3}$ nanoparticles of sizes 20 to $50 \mathrm{~nm}$ was synthesized by Zhu et al. [157]. A relatively modest growth in viscosity of nanofluids about $70 \%$ at 4 vol. $\%$ particle loading was their result.

\section{$\mathrm{MgAl}_{2} \mathrm{O}_{4}$ nanofluid}

Zyla et al. [158] studied on the viscosity of diethylene glycol based $\mathrm{MgAl}_{2} \mathrm{O}_{4}$ nanofluids at different shear rates at a very high pressure of $7.5 \mathrm{MPa}$. They found the Newtonian behavior of the nanofluid where the viscosities at such high pressure are higher than that at atmospheric pressure. They also found that the viscosity of this kind of nanofluid is not influenced by the electric field.

\section{$\mathrm{FeC}-\mathrm{H}_{2} \mathrm{O}$ nanofluid}

Huminic et al. [159] investigated the impact of viscosity on a rare kind of nanofluid viz. $\mathrm{FeC}$ - water nanofluids. Their results showed that the viscosity is increased by $20 \%$ due to the addition of $1 \%$ nanoparticle in water. The summary of experimental data on viscosity of nanofluids from different investigations conducted by some researchers is enlisted in Table-3. 
A.K. Patra et al.

International Journal of Thermofluid Science and Technology (2020), Volume 7, Issue 2, Paper No. 070202

Table 3 Summary of experimental data on viscosity of nanofluids in different investigations.

\begin{tabular}{|c|c|c|c|c|c|}
\hline Authors & Nanofluid Type & $\begin{array}{l}\text { Size } \\
(\mathbf{n m})\end{array}$ & $\begin{array}{l}\text { Volume } \\
\text { fraction } \\
(\%)\end{array}$ & Temperature(C) & $\begin{array}{l}\text { Viscosity } \\
\text { ratio } \\
\left(\mu_{n f} / \mu_{b f}\right)\end{array}$ \\
\hline $\begin{array}{l}\text { Chandrasekar et } \\
\text { al. [9] }\end{array}$ & $\mathrm{Al}_{2} \mathrm{O}_{3} /$ water & 43 & $0.33-5$ & Room & $1-2.36827$ \\
\hline Wang et al. [160] & $\mathrm{Al}_{2} \mathrm{O}_{3} /$ water & 28 & $5-6.17$ & Room & $\begin{array}{l}1.855- \\
1.765\end{array}$ \\
\hline Pak and Cho [32] & $\mathrm{Al}_{2} \mathrm{O}_{3} /$ water & 13 & $1.3-2.78$ & Room & $1.615-2.59$ \\
\hline $\begin{array}{l}\text { Nguyen et al. } \\
{[161]}\end{array}$ & $\begin{array}{l}\mathrm{Al}_{2} \mathrm{O}_{3} / \text { water } \\
\mathrm{Al}_{2} \mathrm{O}_{3} / \text { water } \\
\mathrm{Al}_{2} \mathrm{O}_{3} / \text { water } \\
\mathrm{Al}_{2} \mathrm{O}_{3} / \text { water } \\
\mathrm{Al}_{2} \mathrm{O}_{3} / \text { water }\end{array}$ & $\begin{array}{l}36-47 \\
47 \\
36 \\
47 \\
36\end{array}$ & $\begin{array}{l}0-13 \\
1 \\
1 \\
9 \\
9\end{array}$ & $\begin{array}{l}\text { Room } \\
20-43-71 \\
20-43-71 \\
20-45-54 \\
20-58\end{array}$ & $\begin{array}{l}4.315-5.44 \\
1.128- \\
1.035- \\
1.129 \\
1.223- \\
1.066- \\
1.145 \\
4.446- \\
3.550- \\
3.801 \\
5.311- \\
4.368\end{array}$ \\
\hline Kole and Dey[39] & $\begin{array}{l}\mathrm{Al}_{2} \mathrm{O}_{3}-\mathrm{Car} \text { coolant } \\
\mathrm{Al}_{2} \mathrm{O}_{3}-\mathrm{Car} \text { coolant } \\
\mathrm{Al}_{2} \mathrm{O}_{3}-\mathrm{Car} \text { coolant }\end{array}$ & $\begin{array}{l}<50 \\
<50 \\
<50\end{array}$ & $\begin{array}{l}0.1-1.5 \\
0.1-1.5 \\
0.1-1.5\end{array}$ & $\begin{array}{l}10 \\
30 \\
45\end{array}$ & $\begin{array}{l}1-2.096 \\
1.033- \\
2.352 \\
1.030- \\
2.459\end{array}$ \\
\hline $\begin{array}{l}\text { Murshed et al. } \\
{[12]}\end{array}$ & $\mathrm{Al}_{2} \mathrm{O}_{3}$-DIW & 80 & $1-5$ & Room & $\begin{array}{l}1.03597- \\
1.82734\end{array}$ \\
\hline Prasher et al. [20] & $\begin{array}{l}\mathrm{Al}_{2} \mathrm{O}_{3}-\mathrm{PG} \\
\mathrm{Al}_{2} \mathrm{O}_{3}-\mathrm{PG} \\
\mathrm{Al}_{2} \mathrm{O}_{3}-\mathrm{PG} \\
\mathrm{Al}_{2} \mathrm{O}_{3}-\mathrm{PG} \\
\mathrm{Al}_{2} \mathrm{O}_{3}-\mathrm{PG} \\
\mathrm{Al}_{2} \mathrm{O}_{3}-\mathrm{PG}\end{array}$ & $\begin{array}{l}27-50 \\
27-50 \\
27-40- \\
50 \\
27-40- \\
50 \\
27-40- \\
50 \\
27-40- \\
50\end{array}$ & $\begin{array}{l}0.5 \\
2 \\
3 \\
3 \\
3 \\
3\end{array}$ & $\begin{array}{l}30 \\
30 \\
30 \\
40 \\
50 \\
60\end{array}$ & $\begin{array}{l}1.070- \\
1.053 \\
1.236- \\
1.153 \\
1.277- \\
1.363- \\
1.218 \\
1.291- \\
1.376- \\
1.231 \\
1.306- \\
1.349- \\
1.246 \\
1.306- \\
1.349-\end{array}$ \\
\hline
\end{tabular}


A.K. Patra et al.

International Journal of Thermofluid Science and Technology (2020), Volume 7, Issue 2, Paper No. 070202

\begin{tabular}{|c|c|c|c|c|c|}
\hline & & & & & 1.267 \\
\hline $\begin{array}{l}\text { Schmidt et al. } \\
{[163]}\end{array}$ & $\begin{array}{l}\mathrm{Al}_{2} \mathrm{O}_{3} \text {-decane } \\
\mathrm{Al}_{2} \mathrm{O}_{3} \text {-PAO }\end{array}$ & $\begin{array}{l}40 \\
40\end{array}$ & $\begin{array}{l}0-1 \\
0-1\end{array}$ & $\begin{array}{l}\text { Room } \\
\text { Room }\end{array}$ & $\begin{array}{l}1-1.086 \\
1-1.073\end{array}$ \\
\hline $\begin{array}{lll}\text { Anoop et } & \text { al. } \\
{[162]} & & \end{array}$ & $\begin{array}{l}\mathrm{Al}_{2} \mathrm{O}_{3} \text {-water } \\
\mathrm{Al}_{2} \mathrm{O}_{3} \text {-water } \\
\mathrm{Al}_{2} \mathrm{O}_{3} \text {-EG } \\
\mathrm{CuO}-\mathrm{EG}\end{array}$ & $\begin{array}{l}95 \\
100 \\
100 \\
152 \\
\end{array}$ & $\begin{array}{l}0-7 \\
0-7 \\
0-7 \\
0-7\end{array}$ & $\begin{array}{l}20 \\
20 \\
20 \\
20\end{array}$ & $\begin{array}{l}1-1.772 \\
1-1.572 \\
1-1.298 \\
1-1.321\end{array}$ \\
\hline $\begin{array}{l}\text { Nguyen et al. } \\
{[44]}\end{array}$ & $\begin{array}{l}\mathrm{CuO} \text {-water } \\
\mathrm{CuO} \text {-water } \\
\mathrm{CuO} \text {-water } \\
\mathrm{CuO} \text {-water }\end{array}$ & $\begin{array}{l}29 \\
29 \\
29 \\
29\end{array}$ & $\begin{array}{l}1 \\
4 \\
7 \\
9\end{array}$ & $\begin{array}{l}20-67 \\
20-63 \\
20-57 \\
20-45-51\end{array}$ & $\begin{array}{l}1.188- \\
1.112 \\
2.147- \\
1.840 \\
4.409- \\
3.566 \\
9.776- \\
6.939- \\
7.284\end{array}$ \\
\hline $\begin{array}{l}\text { Namburu et al. } \\
{[64]}\end{array}$ & $\begin{array}{l}\text { CuO-ethylene } \\
\text { CuO-ethylene } \\
\text { CuO-ethylene } \\
\mathrm{CuO} \text {-ethylene } \\
\mathrm{CuO} \text {-ethylene } \\
\text { CuO-ethylene }\end{array}$ & $\begin{array}{l}29 \\
29 \\
29 \\
29 \\
29 \\
29\end{array}$ & $\begin{array}{l}1 \\
2 \\
3 \\
4 \\
5 \\
6.12\end{array}$ & $\begin{array}{l}-35--30-50 \\
-35--30-50 \\
-35--20-50 \\
-35--30-50 \\
-35--30-50 \\
-35-50\end{array}$ & $\begin{array}{l}1.145- \\
1.230- \\
1.102 \\
1.675- \\
1.780- \\
1.399 \\
1.802- \\
1.950- \\
1.613 \\
2.396- \\
2.523- \\
1.929 \\
3.117- \\
3.286- \\
2.375 \\
4.537- \\
3.032\end{array}$ \\
\hline $\begin{array}{l}\text { Kwak and Kim } \\
{[68]}\end{array}$ & CuO-ethylene & $10-30$ & $0.001-1$ & Room & $1-1.04855$ \\
\hline He et al. [164] & $\mathrm{TiO}_{2}$-Water & 20 & $0.125-1$ & Room & $1.11-2.41$ \\
\hline $\begin{array}{l}\mathrm{He} \text { and Zheng } \\
{[165]}\end{array}$ & $\mathrm{TiO}_{2}-\mathrm{Bacl}_{2} /$ water & - & $\begin{array}{l}0.167- \\
1.13\end{array}$ & Room & $\begin{array}{l}1.029- \\
1.319\end{array}$ \\
\hline Ling et al. [166] & $\mathrm{TiO}_{2}$-Water & 35 & $0-0.225$ & Room & 1.072 \\
\hline Chen et al. [167] & $\begin{array}{l}\mathrm{TiO}_{2} \text {-EG } \\
\mathrm{TiO}_{2} \text {-water } \\
\mathrm{TiO}_{2} \text {-EG } \\
\mathrm{TiO}_{2} \text {-Water }\end{array}$ & $\begin{array}{l}10 \times 100 \\
10 \times 100 \\
25 \\
25\end{array}$ & $\begin{array}{l}1.8 \\
0.1-0.6 \\
0.25-1.2 \\
0.1-1.86\end{array}$ & $\begin{array}{l}\text { Room } \\
\text { Room } \\
\text { Room } \\
\text { Room }\end{array}$ & $\begin{array}{l}1.72 \\
1.01-1.82 \\
1.03-1.11 \\
1.005-1.23\end{array}$ \\
\hline Mahbubul etal. [17] & $\mathrm{TiO}_{2}-\mathrm{R} 123$ & 21 & $0.5-2$ & Room & $1.013-1.052$ \\
\hline
\end{tabular}


A.K. Patra et al.

International Journal of Thermofluid Science and Technology (2020), Volume 7, Issue 2, Paper No. 070202

\begin{tabular}{|c|c|c|c|c|c|}
\hline $\begin{array}{l}\text { Yiamsawas et al. } \\
{[168]}\end{array}$ & $\begin{array}{l}\mathrm{TiO}_{2^{-}} \\
\mathrm{EG} / \text { Water(20/80wt\%) }\end{array}$ & 21 & $1-4$ & Room & $1.136-1.60$ \\
\hline $\begin{array}{l}\text { Arulprakasajothi } \\
\text { et al. [60] }\end{array}$ & $\mathrm{TiO}_{2}$-Water & 32 & $0.1-0.75$ & Room & $\begin{array}{l}1.005- \\
1.021\end{array}$ \\
\hline Chen et al. [134] & $\begin{array}{l}\text { CNTs-DW } \\
\text { CNTs-DW } \\
\text { CNTs-DW } \\
\text { CNTs-DW } \\
\text { CNTs-DW }\end{array}$ & $\begin{array}{l}15-30 \\
15-30 \\
15-30 \\
15-30 \\
15-30\end{array}$ & $\begin{array}{l}0.2 \\
0.4 \\
0.6 \\
0.8 \\
1\end{array}$ & $\begin{array}{l}6-65 \\
6-65 \\
6-60 \\
6-65 \\
10-60\end{array}$ & $\begin{array}{l}0.930- \\
1.706 \\
0.951- \\
1.407 \\
1.045- \\
1.334 \\
1.009- \\
1.479 \\
1.356- \\
1.479\end{array}$ \\
\hline Lee et al. [81] & $\begin{array}{l}\mathrm{SiC} / \mathrm{DIW} \\
\mathrm{SiC} / \mathrm{DIW} \\
\mathrm{SiC} / \mathrm{DIW} \\
\mathrm{SiC} / \mathrm{DIW} \\
\mathrm{SiC} / \mathrm{DIW} \\
\mathrm{SiC} / \mathrm{DIW}\end{array}$ & $\begin{array}{l}\leq 100 \\
\leq 100 \\
\leq 100 \\
\leq 100 \\
\leq 100 \\
\leq 100\end{array}$ & $\begin{array}{l}0.001 \\
0.1 \\
1 \\
2 \\
3 \\
0-3\end{array}$ & \begin{tabular}{|l|}
$30-70$ \\
$30-70$ \\
$30-70$ \\
$30-70$ \\
$30-70$ \\
30
\end{tabular} & $\begin{array}{l}1.1763-1 \\
1.285- \\
1.077 \\
1.458- \\
1.512 \\
1.938- \\
1.621 \\
2.024- \\
1.761 \\
1-2.018\end{array}$ \\
\hline Yu et al. [80] & SiC-Water & 170 & 3.7 & $25-70$ & 1.7 \\
\hline $\begin{array}{l}\text { Masuda et al. } \\
\text { [77] }\end{array}$ & $\mathrm{SiO}_{2}$-water & 12 & 2.4 & 12 & 3 \\
\hline $\begin{array}{ll}\text { Tavman } & \text { and } \\
\text { Turgut [76] }\end{array}$ & $\mathrm{SiO}_{2}$-water & 12 & 1.85 & $20-50$ & 1.9 \\
\hline Azmi et al. [59] & $\mathrm{SiO}_{2}$-water & 50 & 4 & 30 & 1.49 \\
\hline $\begin{array}{l}\text { Tseng and Chen } \\
{[169]}\end{array}$ & Nickel-Terpineol & -300 & $3-10$ & 25 & $\begin{array}{l}4.396- \\
474.725\end{array}$ \\
\hline Zhu et al. [157] & $\mathrm{CaCO}_{3}$-water & $20-50$ & $0-4$ & Room & $1-1.692$ \\
\hline $\begin{array}{l}\text { Huminic et al. } \\
{[159]}\end{array}$ & FeC-water & $7-14$ & 1 & $15-70$ & $1.275-1.203$ \\
\hline
\end{tabular}

\section{Role of Models on the Viscosity of Nanofluids}

\subsection{Theoretical Models}

In the past decades, many theoretical models on viscosity of nanofluids have been developed by researchers. The most classic and pioneer model was developed by Einstein [170]. This model can be used in low concentrations of below 2 vol.\% because the model 


\section{A.K. Patra et al.}

International Journal of Thermofluid Science and Technology (2020), Volume 7, Issue 2, Paper No. 070202

considered the hard sphere particles and non-interaction among them. The Einstein model reads

$$
\frac{\mu_{n f}}{\mu_{b f}}=1+2.5 \phi
$$

where $\mu_{n f}$ is the dynamic viscosity of the nanofluid, $\mu_{b f}$ is the dynamic viscosity of base fluids and $\phi$ is the nanoparticle volume fraction.

After Einstein's precious gift to the society, many researchers have been succeeded in accomplishing new eye-catching models in amending or upgrading it. Brinkman [171] extended the Einstein model considering a little higher volume fraction of $4 \%$ and provided his model as:

$$
\mu=\frac{\mu_{f}}{(1-\phi)^{2.5}}
$$

Further, de Bruijin [172] also extended Einstein model to a higher concentration as follows:

$$
\mu=\mu_{f}\left(1-2.5 \phi+1.55 \phi^{2}\right)
$$

Batchelor [173] introduced the effect of Brownian motion and interactions of hard spherical particles and developed a correlation as:

$$
\mu=\mu_{f}\left(1+2.5 \phi+6.5 \phi^{2}\right)
$$

Considering the effect of Brownian motion and mutual forces in suspension Vand [174] proposed two equations to determine the viscosity of suspension as:

$$
\left.\begin{array}{l}
\log \left(\frac{\mu}{\mu_{f}}\right)=\frac{2.5 \phi+2.5 \phi^{2}}{1-0.609 \phi} \\
\mu=\mu_{f}\left(1+2.5 \phi+7.34 \phi^{2}\right)
\end{array}\right\}
$$

Lundgren [175] developed a formula based on the Taylor series expansion as:

$$
\mu=\mu_{f}\left(1+2.5 \phi+6.5 \phi^{2}+O\left(\phi^{3}\right)\right)
$$

In a study Guo et al. [176] declared that small particle size will induce higher viscosity in nanofluids, and they upgraded Batchelor's correlation associated with particle size effect and then developed his own correlation as follows:

$$
\mu=\mu_{f}\left(1+2.5 \phi+6.5 \phi^{2}\right)(1+350 \phi / d)
$$

where $d$ is the particle radius.

Considering the particle radius and inter-particle distance, Graham [177] developed a correlation similar to Einstein model as:

$$
\left.\begin{array}{c}
\mu=\mu_{f}\left[(1+2.5 \phi)+\frac{4.5}{(l / d)(2+l / d)(1+l / d)^{2}}\right] \\
\mu=\mu_{f}\left(1+2.5 \phi+6.5 \phi^{2}\right)(1+350 \phi / d)
\end{array}\right\}
$$

where $d$ is the particle radius and $l$ is the inter-particle distance.

Considering higher volume concentrations, Thomas et al. [178] developed correlation as follows: 


$$
\frac{\mu_{n f}}{\mu_{b f}}=\left(1+2.5 \phi+10.5 \phi^{2}+0.00273 e^{166 \phi}\right)
$$

Krieger and Dougherty [179] presented a correlation where they have adopted the difference of viscosity in different shear rate. The resulting model is as follows:

$$
\mu_{n f}=\mu_{f}\left(1-\frac{\phi}{\phi_{m}}\right)^{[\eta] \phi_{m}}
$$

Where $\phi_{m}$ is the maximum particle volume concentration, which is between 0.495 to 0.54 for static fluid and 0.605 for high shear rates. [ $\eta$ ] is the intrinsic viscosity, whose typical value for mono disperse suspensions of hard spheres is 2.5 .

Chen et al. [63] modified Krieger and Dougherty model by taking into consideration the packing volume fraction of an imaginary sphere possessing clusters based on fractal theory. Their modified form of correlation is

$$
\mu_{n f}=\mu_{f}\left(1-\frac{\phi_{c l}}{\phi_{m}}\right)^{[\eta] \phi_{m}}
$$

where $\phi_{c l}$ is the volume fraction of clusters.

Jeffrey and Acrivos [180] developed another model for the viscosity of non-dilute suspensions of rod-like particles in extensional flow. The model is as follows:

$$
\mu_{e f f}=\mu_{f}\left\{3+\frac{4}{3}\left(\frac{\phi r^{2}}{\ln \left(\frac{\pi}{\phi}\right)}\right)\right\}
$$

This formula reveals that even though $\phi$ is small, the factor $r^{2}$ causes substantial increase in relative viscosity $\left(\frac{\mu_{e f f}}{\mu_{f}}\right)$ over the Newtonian value of 3 .

Taking interfacial layers surrounding the clusters into consideration, Selvakumar and Dhinakaran [181] upgraded Chen et al's model and developed the new model as

$$
\begin{aligned}
& \mu_{n f}=\mu_{f}\left(1-\frac{\phi_{e c l}}{\phi_{m}}\right)^{[\eta] \phi_{m}} \\
& \phi_{e c l}=\phi_{c l}(1+\beta)^{3}
\end{aligned}
$$

where $\phi_{e c l}$ is the effective volume fraction of the cluster with interfacial layers. $\beta$ is the ratio of interfacial layer thickness to the average cluster radius.

In order to establish a relationship between viscosity with the volume concentration and the maximum particle volume concentration, Franken and Acrivos [182] proposed a model as follows: 


$$
\frac{\mu_{n f}}{\mu_{b f}}=\frac{9\left(\frac{\phi}{\phi_{m}}\right)^{\frac{1}{3}}}{8\left[1-\left(\frac{\phi}{\phi_{m}}\right)^{\frac{1}{3}}\right]}
$$

A model meant for calculating the viscosity of suspension with a solid-liquid mixture was developed by Kitano et al. [183]:

$$
\frac{\mu_{n f}}{\mu_{b f}}=\frac{1}{\left[1-\left(\frac{\phi}{\phi_{m}}\right)\right]^{2}}
$$

The power law model to determine the viscosity of nanofluids at higher volume fraction more than $2 \%$ was developed by Nielsen [184]. The model is as follows:

$$
\mu_{n f}=\mu_{f}(1+1.5 \phi) e^{\frac{\phi_{m}}{1-\phi_{m}}}
$$

It is important to mention here that the abov ume concentration. However, the viscosity of nanofluids can also be influenced by other important factors such as temperature and density of particles. In view of this some authors taking such aspects into consideration developed some new models.

Masoumi et al. [185] considered the effect of density of nanoparticles, Brownian motion, temperature and diameter of nanoparticles and developed their model accordingly as

$$
\mu_{n f}=\mu_{f}+\frac{\rho_{p} V_{B} d}{72 c l}
$$

where $\rho_{p}$ is the density of nanoparticle, $V_{B}=\frac{1}{d} \sqrt{\frac{18 k_{B} T}{\pi \rho_{p} d}}$ is the Brownian velocity, $k_{B}$ is the Boltzmann's constant, $l=\left(\frac{\pi}{6 \phi} d\right)^{\frac{1}{3}}$ is the distance between the centers of the nanoparticles from each other. In the above equation $c$ is the correction factor which is a function of nanoparticle diameter and temperature as

$$
c=\left(c_{1} \phi+c_{2}\right) d+\left(c_{3} \phi+c_{4}\right)
$$

Here the constant values $c_{1}=-1.133 e^{-6}, c_{2}=-2.771 e^{-6}, c_{3}=-9 e^{-8}, c_{4}=3.93 e^{-7}$ have been extracted by curve fitting of experimental data.

Table 4 incorporates the main proposed models regarding the viscosity of nanofluids.

Table 4 General theoretical model for nanofluids viscosity as a function of volume fraction

\begin{tabular}{|l|l|}
\hline \multicolumn{1}{|c|}{ Reference } & \multicolumn{1}{c|}{ Formula } \\
\hline Einstein [170] & $\mu_{\text {eff }}=\left(1+2.5 \varphi_{p}\right)$ \\
\hline Brinkman [171] & $\mu_{\text {eff }}=\frac{1}{\left(1-\varphi_{p}\right)^{2 / 5}}=\left(1+2.5 \varphi_{p}+4.375 \varphi_{p}^{2}+\cdots\right)$ \\
\hline
\end{tabular}


A.K. Patra et al.

International Journal of Thermofluid Science and Technology (2020), Volume 7, Issue 2, Paper No. 070202

\begin{tabular}{|l|l|}
\hline Lundgern [175] & $\mu_{\text {eff }}=\frac{1}{1-2.5 \varphi_{p}}=\left(1+2.5 \varphi_{p}+6.25 \varphi_{p}^{2}+\cdots\right)$ \\
\hline Batchelor [173] & $\mu_{\text {eff }}=\left(1+\pi \varphi_{p}+k_{H} \varphi_{p}^{2}\right)=\left(1+2.5 \varphi_{p}+6.2 \varphi_{p}^{2}\right)$ \\
\hline $\begin{array}{l}\text { Frankel and Acrivos } \\
\text { [182] }\end{array}$ & $\mu_{\text {eff }}=\left(\frac{9}{8} \frac{\left(\frac{\varphi_{p}}{\varphi_{p \max }}\right) 1 / 3}{1-\left(\frac{\varphi_{p}}{\varphi_{\text {max }}}\right) 1 / 3}\right)$ \\
\hline Graham [177] & $\mu_{\text {eff }}=\left(1+2.5 \varphi_{p}\right)+\left[\frac{4.5}{\left(\frac{h}{r_{p}}\right) \cdot\left(2+\frac{h}{r_{p}}\right)^{2}}\right]$ \\
\hline Mooney [186] & $\mu_{\text {eff }}=\exp \left(\frac{2.5 \varphi_{p}}{1-k \varphi_{p}}\right)=\left\{1+\frac{2}{5 \varphi_{p}}+\left[\frac{3}{125}+\left(\frac{2}{5 k}\right) \varphi_{p}^{2}+\cdots\right\} \rightarrow 1.35\right.$ \\
\hline Eilers [187] & $\mu_{\text {eff }}=\mu_{f}\left[1+\frac{1.25 \varphi_{p}}{\frac{1-\varphi_{p}}{0.78}}\right]=\left(1+2.5 \varphi_{p}+4.75 \varphi_{p}^{2}+\cdots\right)$ \\
\hline Saito [188] & $\mu_{\text {eff }}=\mu_{f}\left[1+\frac{1.25 \varphi_{p}}{1-\varphi_{p}} \varphi_{p}\right]=\left(1+2.5 \varphi_{p}+2.5 \varphi_{p}^{2}+\cdots\right)$ \\
\hline
\end{tabular}

Many others [189-192] worked in the related areas. Fig.8 illustrates some analytical models which are compared with some new experimental works in terms of viscosity estimation.

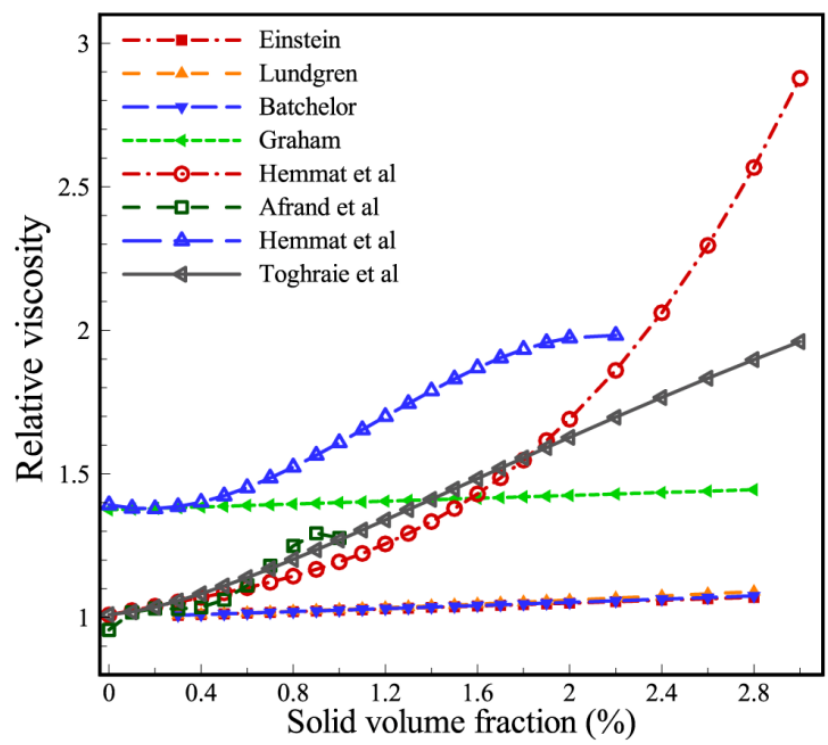

Fig. 8 Comparison of theoretical models with experimental results for the viscosity estimation of nanofluids (Khodadadi et al. [139]).

From Fig. 8 it is evident that the results of the theory relations are far from experimental facts and, except for very low volume fractions, are unable to estimate the nanofluids' viscosity and for which further research is needed. 
A.K. Patra et al.

International Journal of Thermofluid Science and Technology (2020), Volume 7, Issue 2, Paper No. 070202

\subsection{Experimental Correlations}

Nevertheless, many models have been proposed for determining the viscosity of nanofluids the most practicable method is still experimental mean due to the wide range of variations in different samples. The dynamic viscosity of $\mathrm{Al}_{2} \mathrm{O}_{3}$ - water nanofluid depends upon the temperature and volume fraction (Nguyen et al. [161]). They observed the effects in the temperature range between $22^{\circ} \mathrm{C}$ and $75^{\circ} \mathrm{C}$ and a volume fraction of $1-9.4 \%$. The correlation that was proposed for aluminum oxide particles with diameters of 47 and $36 \mathrm{~nm}$ is as follows:

$$
\frac{\mu_{n f}}{\mu_{b f}}=0.094 e^{14.83 \phi}
$$

Further, they proposed the following two equations considering the effect of temperature for volume fractions of 1 and $4 \%$ of aluminum oxide particles, respectively:

$$
\begin{aligned}
& \frac{\mu_{n f}}{\mu_{b f}}=1.125-0.0007 T \\
& \frac{\mu_{n f}}{\mu_{b f}}=2.1275-0.0215 T+0.002 T^{2}
\end{aligned}
$$

Where $\mathrm{T}$ is the fluid temperature in $\left(\left(0^{\circ} \mathrm{C}\right)\right.$

The above correlations are unable to estimate the viscosity of nanofluids over a wide range of volume fractions. Maiga et al. [193] used curve-fit on the empirical data of Wang et al. [160], and developed the model:

$$
\mu_{\text {eff }}=1+7.3+123 \phi^{2}
$$

The viscosity of suspended copper nanoparticles at a temperature range of $5-50^{\circ} \mathrm{C}$ can be calculated by a new correlation (Kulkarni et al. [78]):

$$
\ln \left(\frac{\mu_{n f}}{\mu_{b f}}\right)=A\left(\frac{1}{T}\right)-B
$$

The rheological properties of a suspended blend of copper oxide nanoparticles in a mixture of water and ethylene glycol $(60: 40 \mathrm{wt} \%)$ was experimentally examined by Namburu et al. [64]. They determined viscosity in the volume fractions range between 0 and $6.12 \%$ and temperatures between $35^{\circ} \mathrm{C}$ and $50^{\circ} \mathrm{C}$. Based on their results, they developed an experimental model that relates the viscosity with temperature and the nanoparticle volume fraction and the temperature as follows:

$$
\ln \left(\frac{\mu_{n f}}{\mu_{b f}}\right)=A e^{-B T}
$$

where $\mu_{n f}$ is the viscosity of copper oxide nanofluid in terms of centi-Poise (cP), $\mathrm{T}$ is the temperature in Kelvin, the constants $\mathrm{A}$ and $\mathrm{B}$ are functions of nanoparticle volume fraction:

$$
\left.\begin{array}{c}
A=1.8375 \phi^{2}-29.643 \phi+165.56 \\
B=4 \times 10^{-6} \phi^{2}-0.001 \phi+0.0186
\end{array}\right\}
$$

In the above relation, $u$ varies from 0 to $6.12 \%$. They declared that the nanofluid exhibits Newtonian behavior in their study. 


\section{A.K. Patra et al.}

International Journal of Thermofluid Science and Technology (2020), Volume 7, Issue 2, Paper No. 070202

Kao et al. [194] investigated experimentally the behavior of aluminum oxide nanoparticle in a mixture of ethylene glycol-water. They found that nanofluids exhibits nonNewtonian Behavior at temperatures ranging from $-35^{\circ} \mathrm{C}$ to $0^{\circ} \mathrm{C}$ while they show Newtonian behavior at temperatures ranging from $0^{\circ} C$ to $90^{\circ} C$. In their study they considered the diameter of nanoparticles as $53 \mathrm{~nm}$ and the volume fractions ranged from 1 to $10 \%$. According to the experimental results, they obtained a correlation for the estimation of viscosity as follows:

$$
\left(\frac{\mu_{n f}}{\mu_{b f}}\right)=A e^{\left(\frac{B}{T}+C \phi\right)}
$$

The values for $\mathrm{A}, \mathrm{B}$, and $\mathrm{C}$ are $A=1.2200 \times 10^{-6}$ (low temperature region), $A=2.3920 \times 10^{-6}$ (high temperature region), $B=4285$ (low temperature region), $B=2903$ (high temperature region) and $C=0.1448$ (low temperature region), $C=0.1265$ (high temperature region).

Vajjha [22] obtained a more complete model for nanoparticles of aluminum oxide and copper oxide in a mixture of water and ethylene glycol (60:40 wt \%):

$$
\left(\frac{\mu_{n f}}{\mu_{b f}}\right)=A e^{B \phi}
$$

where the constants $\mathrm{A}$ and $\mathrm{B}$ at temperatures ranged from $20^{\circ} \mathrm{C}$ to $90^{\circ} \mathrm{C}$ for aluminum oxide nanoparticles, are: $\mathrm{A}=0.983, \mathrm{~B}=12.959$ and for copper oxide nanoparticles: $\mathrm{A}=0.9197$, $\mathrm{B}=22.8539$. Table 5 incorporates the experimental correlations developed by many researchers.

\begin{tabular}{|c|c|c|}
\hline Reference & Correlations & Nanofluids \\
\hline Nguyen [161] & $\begin{aligned} \frac{\mu_{n f}}{\mu_{b f}} & =0.904 e^{14.83 \varphi} \\
\frac{\mu_{n f}}{\mu_{b f}} & =\left[1+2.5 \varphi+150 \varphi^{2}\right] \\
\frac{\mu_{n f}}{\mu_{b f}} & =1.125-0.0007 T \\
\frac{\mu_{n f}}{\mu_{b f}} & =2.1275-0.0215 T+0.002 T^{2}\end{aligned}$ & $\begin{array}{l}\text { Aluminum oxide/ } \\
\text { Water }(47 \mathrm{~nm}) \\
\text { Aluminum oxide/ } \\
\text { Water }(36 \mathrm{~nm}) \\
\text { Aluminum oxide/ } \\
\text { Water ( } 1 \% \text { vol) } \\
\text { Aluminum oxide/ } \\
\text { Water ( } 4 \% \text { vol) }\end{array}$ \\
\hline Maiga [193] & $\frac{\mu_{n f}}{\mu_{b f}}=\left(1+7.3 \varphi+123 \varphi^{2}\right)$ & $\begin{array}{l}\text { Aluminum oxide- } \\
\text { Water or EG }\end{array}$ \\
\hline Kulkarni [78] & $\operatorname{Ln}\left(\frac{\mu_{n f}}{\mu_{b f}}\right)=A\left(\frac{1}{T}\right)-B$ & $\mathrm{Cu} /$ Water \\
\hline Namburu [64] & $\begin{array}{l}\log \frac{\mu_{n f}}{\mu_{b f}}=\left(165.56-29.643 \varphi+1.8375 \varphi^{2}\right) * \exp [(0.0186-0.001 \varphi+4 * \\
\left.\left.10^{-6} \varphi^{2}\right) T\right]\end{array}$ & $\begin{array}{l}\text { Copper } \\
\text { oxide/Water: EG } \\
(60: 40)\end{array}$ \\
\hline
\end{tabular}

Table 5 Summary of experimental correlations conducted in the viscosity field 
A.K. Patra et al.

International Journal of Thermofluid Science and Technology (2020), Volume 7, Issue 2, Paper No. 070202

\begin{tabular}{|l|l|l|}
\hline Vajjha [22] & $\begin{array}{l}\frac{\mu_{n f}}{\mu_{b f}}=A e^{-B T} \\
\text { Abu-Nada [195] }\end{array}$ & $\begin{array}{l}\text { Aluminum } \\
\text { oxide/copper oxide } \\
\text { Water: EG (60:40) }\end{array}$ \\
\hline $\begin{array}{c}\mu_{n f}=-0.155-\frac{19.582}{T}+0.794 \varphi+\frac{2094.47}{T^{2}}-0.192 \varphi^{2}-8.11 \frac{\varphi}{T} \\
T^{3}\end{array}$ & $\begin{array}{l}\text { Aluminum oxide/ } \\
\text { Water }\end{array}$ \\
\hline $\begin{array}{l}\text { Duangthongsuk } \\
\text { and Wongwises } \\
\text { [196] }\end{array}$ & $\begin{array}{l}\frac{\mu_{n f}}{\mu_{b f}}=a+b \varphi+c \varphi^{2} \\
T^{2}\end{array}$ & $\begin{array}{l}\text { Titanium de oxide } \\
\text { Water }\end{array}$ \\
\hline
\end{tabular}

\section{Parameters Influencing the Viscosity of Nanofluids}

This section reveals information how different effective parameters such as surfactants addition, the temperature, nanoparticle volume fraction, base fluid type, $\mathrm{pH}$ value, production technique, etc. influence the viscosity of diversified nanofluids (contributing major role in enhancing the heat transfer of nanofluids).

\subsection{Surfactants addition}

Stability of nanofluids is greatly influenced by the nature of the base fluid and nanoparticles. For instance, water as a base fluid is polar while oil non-polar. Also, oxide nanoparticles are hydrophilic whereas CNTs are hydrophobic in nature. Thus, the addition of surfactants can be regarded as most appropriate method to upgrade dispersion of nanoparticles in the base fluids like dispersion of CNTs in water or oxide particles in the oil. Surfactants act as a bridge to attach nanoparticles to the base fluids in order to avert particles aggregation (lowers the viscosity). Surfactants are the products used in the chemical industries, detergents, pharmaceuticals, drilling mud's etc. These are widely used for developing even dispersion of nanoparticles in the base fluid. Surfactants are oil soluble as well as water soluble. Therefore, the selection of surfactant depends on the nature of the base fluid. Surfactants can be negatively charged (anionic), positively charged (cationic), neutral (non-ionic) or both negatively and positively charged (amphoteric) based on the charge on its head group. Mainly, the nanoparticles' surface charge and the base fluid considered determine the surfactant to be selected. This is because the use of surfactants may be unfavorable for the applications at elevated temperatures [197-198].

\subsection{Particle volume concentration}

Most of the experimental studies on nanofluids deal with the effect of particle volume concentration on viscosity. Many researchers agreed with the consensus that the increase in the particle concentration upsurges the viscosity [199] and belittles the stability. Therefore, researchers carried out studies on nanofluids by keeping the particle concentration at a limit usually below $10 \mathrm{wt} \%$. The behavior of copper oxide-ethylene glycol, aluminum oxideethylene glycol and aluminum oxide-water nanofluids was analyzed by Anoop et al. [162]. They studied the variation of viscosity at temperature ranging from $20^{\circ} \mathrm{C}$ to $50^{\circ} \mathrm{C}$ and volume fraction of $0.5,1,2,4$ and $6 \%$, and observed that increasing particle concentration 


\section{A.K. Patra et al.}

International Journal of Thermofluid Science and Technology (2020), Volume 7, Issue 2, Paper No. 070202

escalates the viscosity of the fluid. Behi and Mirmohammadi [200] reported that augmented nanoparticle volume fraction from 0.6 to 0.8 , a $1.7 \%$ enhances the viscosity. Kole and Dey [39] observed in their study that viscosity as a function of volume fraction. In Fig. 9 variations in viscosity with respect to the volume fraction are presented for some nanofluids.

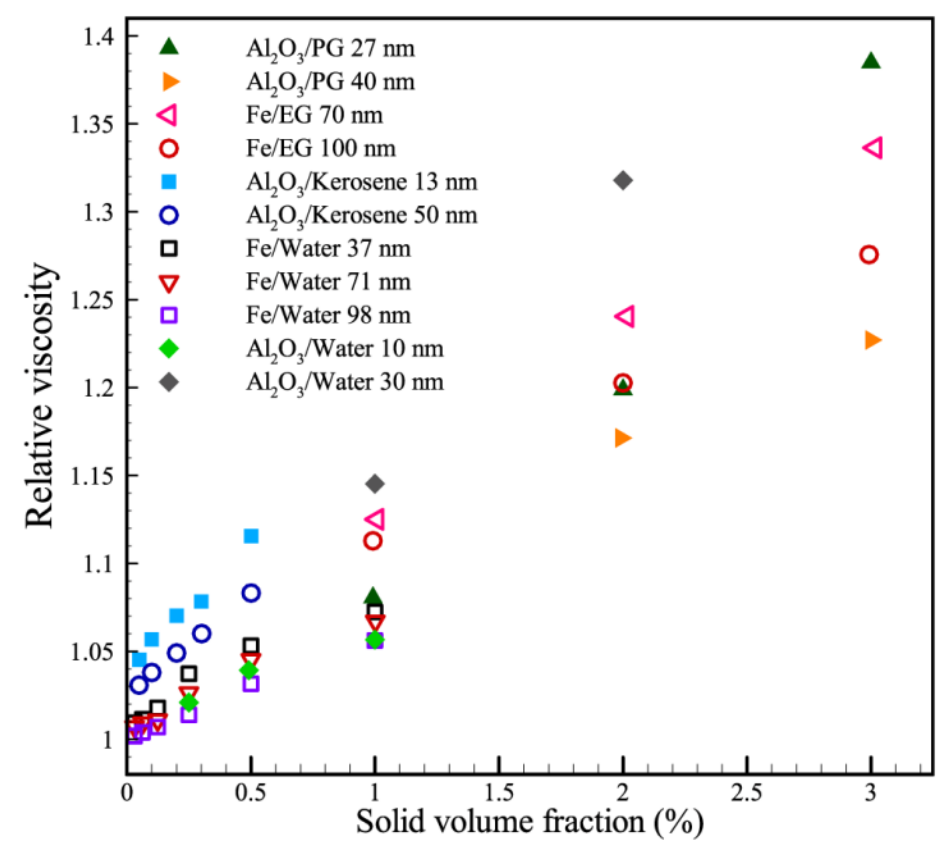

Fig. 9 Relative viscosity variations with respect to the volume fraction for some nanofluids (Khodadadi et al. [139])

It is universally concluded that the enhancement in volume fraction leads to augmentation in viscosity. It is remarkable that the dimensionless relative viscosity has been adopted in Fig. 9. The most appropriate models considering the effect of particle volume fraction are enlisted in Table 6.

Table 6 Summary of viscosity models for given types of nanofluids in different researches

\begin{tabular}{|c|c|c|c|}
\hline Authors & Nanofluids & $\begin{array}{c}\text { Volume } \\
\text { fraction } \\
\operatorname{range}(\%)\end{array}$ & Expressions of viscosity models \\
\hline Namburu et al.[64] & $\mathrm{Al}_{2} \mathrm{O}_{3}$-EG/W & $1.0-10$ & $\log \left(\mu_{n f}\right)=A e^{-B T}$ \\
\hline Buongiorno[201] & $\mathrm{Al}_{2} \mathrm{O}_{3}$-water & $0-10$ & $\mu_{n f} / \mu_{b f}=1+39.11 \varphi+533.9 \varphi^{2}$ \\
\hline Nguyen et al.[161] & $\mathrm{Al}_{2} \mathrm{O}_{3}$-water & $1-4$ & $\mu_{n f} / \mu_{b f}=1.125-0.0007 T$ \\
\hline Maiga et al.[193] & $\mathrm{Al}_{2} \mathrm{O}_{3}$-water & $0.0-6.0$ & $\mu_{n f} / \mu_{b f}=1+7.3 \varphi+123 \varphi^{2}$ \\
\hline Rea et al.[202] & $\mathrm{Al}_{2} \mathrm{O}_{3}$-water & $0.0-6.0$ & $\mu_{n f} / \mu_{b f}=e^{(4.91 \varphi / 0.2092-\varphi)}$ \\
\hline $\begin{array}{l}\text { Naik and } \\
\text { sundar[203] }\end{array}$ & $\mathrm{CuO}-\mathrm{EG} / \mathrm{W}$ & $0.0-1.2$ & $\mu_{n f} / \mu_{b f}=3.444\left(T_{\max } / T_{\min }\right)^{0.514} \varphi^{0.1829}$ \\
\hline Kole and Dey[39] & $\begin{array}{c}\mathrm{Al}_{2} \mathrm{O}_{3} \text {-car engine } \\
\text { coolant }\end{array}$ & $0.1-3.5$ & $\begin{array}{l}\log \left(\mu_{n f}\right)=A e^{-B T} \\
A=-225.245 \varphi^{2}+18.404 \varphi+1.749 \\
B=575.835 \varphi^{3}-32.101 \varphi^{2}+0.148 \varphi+0.01\end{array}$ \\
\hline
\end{tabular}


A.K. Patra et al.

International Journal of Thermofluid Science and Technology (2020), Volume 7, Issue 2, Paper No. 070202

\begin{tabular}{|c|c|c|c|}
\hline Kulkarni et al.[78] & CuO-water & $1.0-6.12$ & $\log \left(\mu_{n f}\right)=A(1 / T)-B$ \\
\hline Nguyen et al.[161] & $\mathrm{CuO}$-water & $1.0-13.0$ & $\mu_{n f} / \mu_{b f}=1.475-0.319 \varphi+0.051 \varphi^{2}+0.009 \varphi^{3}$ \\
\hline Nguyen et al.[161] & $\mathrm{CuO}$-water & $1-4$ & $\mu_{n f} / \mu_{b f}=2.1272-0.0215 T+0.0002 T^{2}$ \\
\hline Sundar et al.[204] & $\begin{array}{c}\mathrm{Fe}_{3} \mathrm{O}_{4}-\mathrm{EG} / \mathrm{W} \\
(\mathrm{EG}: \mathrm{W}=2: 8 \text { or } 4: 6)\end{array}$ & $0.0-1.0$ & $\mu_{n f} / \mu_{b f}=(1+\varphi)^{0.68}$ \\
\hline Sundar et al. [204] & $\begin{array}{l}\mathrm{Fe}_{3} \mathrm{O}_{4}-\mathrm{EG} / \mathrm{W} \\
(\mathrm{EG}: \mathrm{W}=2: 8 \text { or } 4: 6)\end{array}$ & $0.0-1.0$ & $\frac{\mu_{n f}}{\mu_{b f}}=(1+\varphi)^{1.205}$ \\
\hline $\begin{array}{l}\text { Brenner and Condiff } \\
{[205]}\end{array}$ & CNT-Water & - & $\frac{\mu_{n f}}{\mu_{b f}}=(1+n \mu)$ \\
\hline Boboo et al. [206] & MWCNT-Water & $0.0-1.0$ & $\frac{\mu_{n f}}{\mu_{b f}}=1+a \varphi+b \varphi^{2}$ \\
\hline $\begin{array}{l}\text { Vakili-Nezhaad et } \\
\text { al. [207] }\end{array}$ & SWCNT-lubricant & $0.01-0.2$ & $\frac{\mu_{n f}}{\mu_{b f}}=0.2 T^{2}-30.3 T+1048$ \\
\hline Yu et al.[80] & SiC-water & $0.0-3.7$ & $\frac{\mu_{n f}}{\mu_{b f}}=0.00496 e^{\left(\frac{17366}{T}\right)}$ \\
\hline Sharma et al. [208] & SiC-Water & - & $\begin{array}{l}\frac{\mu_{n f}}{\mu_{b f}}=1.4(1+\varphi / 100)^{11.3}\left(1+T_{n f} / 70\right)^{-0.038}+(1+ \\
\left.\frac{d_{p}}{170}\right)^{-0.061}\end{array}$ \\
\hline Namburu et al. [64] & $\mathrm{SiO}_{2}$-EG/W & $2.0-10.0$ & $\begin{array}{l}\log \left(\mu_{n f}\right)=A e^{-B T} \\
\mathrm{~A}=0.1193 \varphi^{3}-1.9289 \varphi^{2}-2.245 \varphi+167.17 \\
\mathrm{~B}=\left(-7 * 10^{-6}\right) \varphi^{2}-0.0004 \varphi+0.0192\end{array}$ \\
\hline Tseng and Lin[37] & $\mathrm{TiO}_{2}$-water & $0.05-0.12$ & $\frac{\mu_{n f}}{\mu_{b f}}=13.47 e^{35.98 \varphi}$ \\
\hline $\begin{array}{l}\text { Duangthongsuk and } \\
\text { Wongwises [196] }\end{array}$ & $\mathrm{TiO}_{2}$-water & $0.2-2.0$ & $\frac{\mu_{n f}}{\mu_{b f}}=a+b \varphi+c \varphi^{2}$ \\
\hline Buongiorno [201] & $\mathrm{TiO}_{2}$-water & $0-10$ & $\frac{\mu_{n f}}{\mu_{b f}}=1+5.45 \varphi+108.2 \varphi^{2}$ \\
\hline
\end{tabular}

\subsection{Particle size}

The general trend of theoretical as well as experimental results shows the viscosity greatly depends on the particle size in the sense that viscosity of nanofluids increases with increasing particle diameter. The effects of the changes in the size of particles on the relative viscosity of the water-based and ethylene glycol-based nanofluids are shown in Fig. 10 and 11 , respectively. 


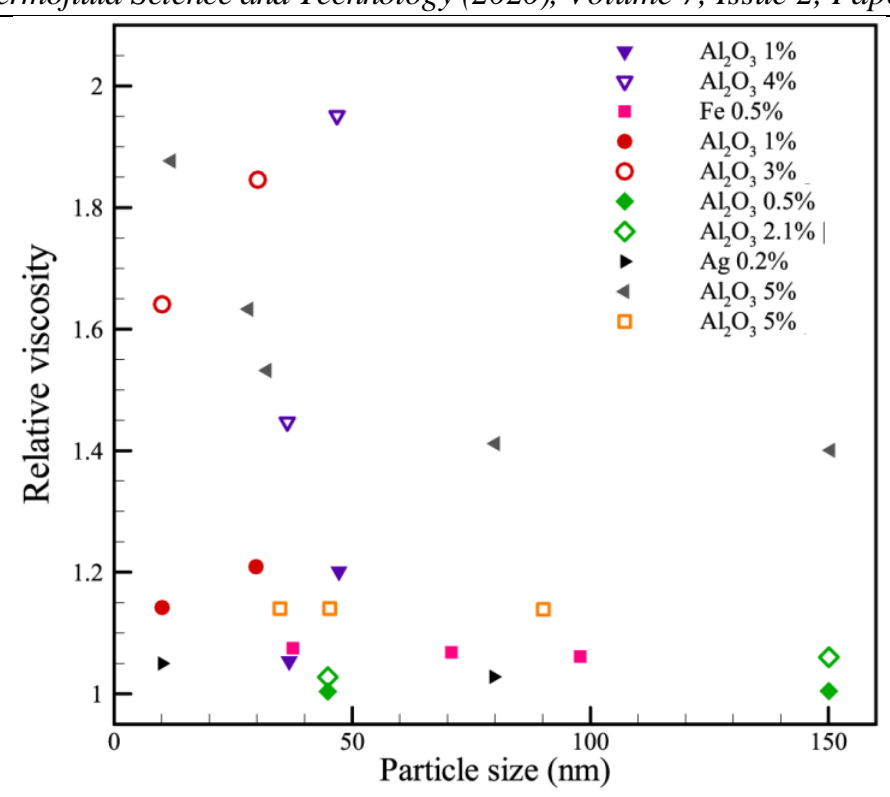

Fig. 10 The effect of changes in the size of particles on the relative viscosity of water-based nanofluids (Khodadadi et al. [139]).

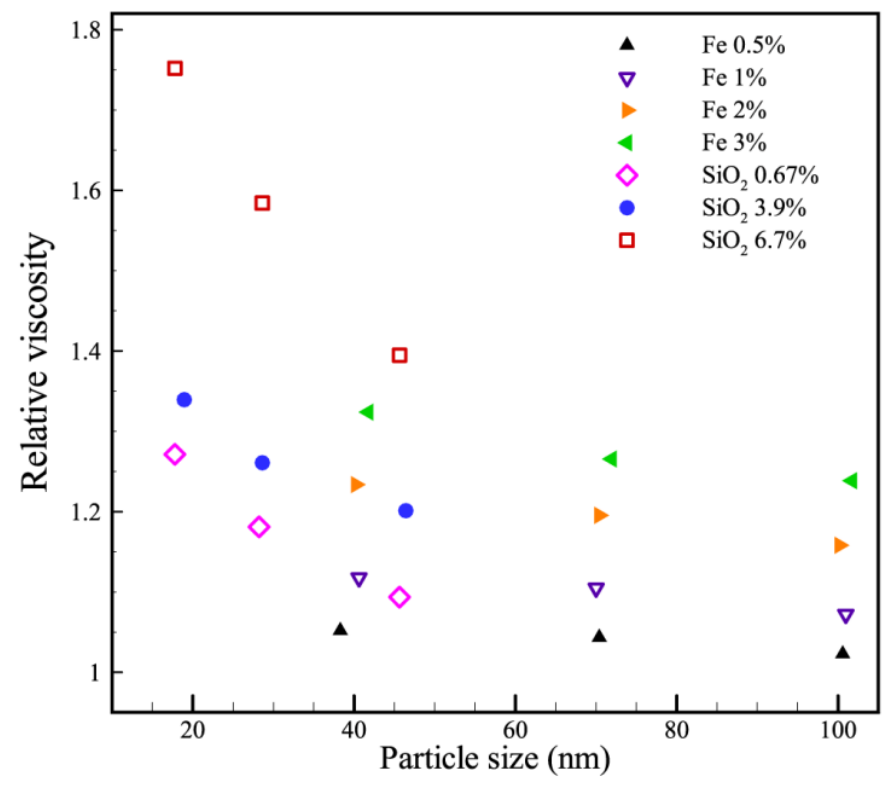

Fig. 11 The effect of changes in the size of particles on the relative viscosity of ethylene glycol-based nanofluids (Khodadadi et al. [139]).

He et al. [209] reported the viscosity of titanium oxide-water nanofluid for different concentrations in different sizes of nanoparticles (95, 145, and $210 \mathrm{~nm}$ ). Although they achieved a contradictory result, such as the result achieved by Lu and Fan [210], they numerically and experimentally examined the viscosity of aluminum oxide-water and aluminum oxide-ethylene glycol in different sizes of nanoparticles, and found that the viscosity of nanoparticles reduces due to increase in particle diameter. From Table 5, it is 
A.K. Patra et al.

International Journal of Thermofluid Science and Technology (2020), Volume 7, Issue 2, Paper No. 070202

inferred that Nguyen et al. [161] proposed some correlations for predicting the viscosity of $\mathrm{Al}_{2} \mathrm{O}_{3}$ - water nanofluid as separated functions of the temperature and volume fraction for different nanoparticles' diameters. However, their correlation could not comply with the effects of temperature and nanoparticles volume fraction simultaneously. Abu-Nada [195] used experimental data reported in Nguyen et al. [161] and proposed a new correlation on the viscosity of $\mathrm{Al}_{2} \mathrm{O}_{3}$-water nanofluid as a function of temperature and nanoparticles volume fraction as follows:

$$
\begin{aligned}
\mu_{n f}= & -0.155-\frac{19.582}{T}+0.794 \phi+\frac{2094.47}{T^{2}}-0.192 \phi^{2}-8.11 \frac{\phi}{T} \\
& -\frac{27463.863}{T^{3}}+0.0127 \phi^{3}+1.6044 \frac{\phi^{2}}{T}+2.1754 \frac{\phi}{T^{2}}
\end{aligned}
$$

Later, Khanafar and Vafai [211] established a general correlation for viscosity in the $\mathrm{Al}_{2} \mathrm{O}_{3}-$ water nanofluid, as a function of the volume fraction, nanoparticle diameter and temperature:

$$
\begin{aligned}
\mu_{e f f}= & -0.4491+\frac{28.837}{T}+0.574 \phi_{p}-0.1634 \phi_{p}^{2}+23.053 \frac{\phi_{p}^{2}}{T^{2}} \\
& +0.0132 \phi_{p}^{3}-2354.735 \frac{\phi_{p}}{T^{3}}+23.498 \frac{\phi_{p}^{2}}{d_{p}^{2}}-3.0185 \frac{\phi_{p}^{3}}{d_{p}^{2}} \\
1 \% \leq & \phi_{p} \leq 9 \%, 20 \leq T\left({ }^{0} C\right) \leq 70,13 \mathrm{~nm} \leq d_{p} \leq 131 \mathrm{~nm}
\end{aligned}
$$

Wen et al. [212] concluded that the nanofluids viscosity decreases with increasing particle diameter, by analyzing the viscosity of aluminum oxide-water and aluminum oxideethylene glycol nanofluids. Usually, particles with two different morphologies such as spherical and cylindrical are commonly used in nanofluids. Nanofluids with cylindrical particles accounts for a greater increase in the viscosity which in turn yields increased pumping energy [213]. Kim et al. [40] investigated the influence of aspect ratio on the viscosity of nanofluids with fibrous and spherical alumina nanoparticles. They found that viscosity increment of fibrous alumina nanofluids was higher than that of the spherical one. Farbod et al. [214] investigated the influence of different morphologies of $\mathrm{CuO}$ (nanoparticles, nanorhombics, and nanorods) on the thermal properties of nanofluids. Abdelhalim et al. [215] found in his investigation that a rise in viscosity of water based gold (Au) nanofluids with larger nanoparticles.

\subsection{Temperature}

Many researchers studied on the effect of temperature on the viscosity of nanofluids along with the effects of other factors. Duangthongsuk and Wongwises [196] studied titanium oxide-water nanofluid in a temperature range of $15^{\circ} \mathrm{C}$ to $50^{\circ} \mathrm{C}$ and a volume of $0.2-3 \%$ and found that a decrease in viscosity causes an increase in temperature. Namburu et al. [64] concluded that nanofluids possess $\mathrm{CuO}$ particles in an ethylene glycol and water mixture, at temperature ranging from $35^{\circ} \mathrm{C}$ to $50^{\circ} \mathrm{C}$, with a volume fraction of $0-6 \%$ behave as nonNewtonian fluids where the viscosity decreases exponentially, with increasing temperature. Prasher et al. [20] and Chen et al. [63] showed the contradiction that the viscosity of nanofluids is independent of temperature. Putra et al. [216] investigated the effect of temperature on viscosity of aluminum oxide-water nanofluid and obtained the following relations: 
A.K. Patra et al.

International Journal of Thermofluid Science and Technology (2020), Volume 7, Issue 2, Paper No. 070202

$$
\begin{aligned}
& \mu_{e f f}=0.034-2 \times 10^{-4} T+2.9 \times 10^{-7} T^{2}, \phi=1 \% \\
& \mu_{e f f}=0.039-2.3 \times 10^{-4} T+3.4 \times 10^{-7} T^{2}, \phi=4 \%
\end{aligned}
$$

Table 7 comprises some of the study carried out regarding the effect of temperature on the viscosity of nanofluids.

Table 7 Studies conducted on the impact of temperature on the viscosity of nanofluids and the related outcomes

\begin{tabular}{|l|l|l|l|l|}
\hline Authors & Nanoparticles & Base fluid & $\begin{array}{l}\text { Temperature } \\
\text { range }\left({ }^{\circ} \square\right)\end{array}$ & $\begin{array}{l}\text { Maximum } \\
\text { relative } \\
\text { viscosity }\end{array}$ \\
\hline Namburu et al. [64] & $\mathrm{SiO}_{2}$ & $\begin{array}{l}\text { EG-water } \\
(60: 40)\end{array}$ & -35 to 50 & 1.625 \\
\hline He et al. [210] & $\mathrm{TiO}_{2}$ & Water & 22 & 1.0716 \\
\hline Prasher et al. [20] & $\mathrm{Al}_{2} \mathrm{O}_{3}$ & PG & $30-60$ & 1.3762 \\
\hline Oliveria et al. [217] & $\mathrm{Ag}$ & Water & Ambient & 1.0458 \\
\hline $\begin{array}{l}\text { Timofeeva et al. } \\
{[218]}\end{array}$ & $\mathrm{SiC}$ & Water & $15-45$ & 1.857 \\
\hline $\begin{array}{l}\text { Merilainen et al. } \\
{[219]}\end{array}$ & $\mathrm{Al}_{2} \mathrm{O}_{3}$ & Water & $10-50$ & 1.65 \\
\hline Kwek et al. [42] & $\mathrm{Al}_{2} \mathrm{O}_{3}$ & Water & 25 & 1.882 \\
\hline $\begin{array}{l}\text { Jarahnejad et al. } \\
{[16]}\end{array}$ & $\mathrm{Al}_{2} \mathrm{O}_{3}$ & Water & $20-50$ & 1.86 \\
\hline $\begin{array}{l}\text { Minakov et al. } \\
{[220]}\end{array}$ & $\mathrm{SiO}_{2}$ & Water & 25 & 1.43 \\
\hline $\begin{array}{l}\text { Chevalier et al. } \\
\text { [221] }\end{array}$ & $\mathrm{SiO}_{2}$ & Ethanol & Ambient & 1.99 \\
\hline
\end{tabular}

Fig. 12 reveals the effect of temperature variations on the viscosity of various nanofluids. According to many research conducted, the nanofluids viscosity decreases by increasing the temperature. Although, few studies have shown that temperature variations have little impact on the relative viscosity of nanofluids, however some other experiments conducted revealed that this ratio will vary with temperature variation. 




Fig. 12 The effect of temperature variations on the viscosity of water based nanofluids with different nano-additives (Khodadadi et al. [139])

\section{$5.5 \mathrm{pH}$}

The $\mathrm{pH}$ of nanofluids affects the viscosity [222] well. Xian-Ju and Xin- Fang [222] studied the effect of $\mathrm{pH}$ on the viscosity of water-based $\mathrm{Cu}$ and $\mathrm{Al}_{2} \mathrm{O}_{3}$ nanofluids. The outcome of the study is that an optimal $\mathrm{pH}$ value yields the lowest viscosity of the nanofluids with a better dispersion behavior.

\subsection{Particle loading}

Halelfadl et al. [138] found that the CNT nanofluids exhibit Newtonian behavior at lower particle loading and a shear thinning behavior at higher loading.

\subsection{Base fluid type}

In an experiment carried out by Xie et al. [223] where nanoparticles dispersed in organic fluids similar to ethylene glycol it was observed that increased viscosity of ethylene glycol-based nanofluids was lower, compared to water-based nanofluids.

\subsection{Nanoclustering}

Because of Van der Waals forces, some nano-clusters are developed. As a result, a passageway with lower thermal resistance is established for the heat transfer [224]. The nanoclustering phenomenon offers a negative effect on nanofluids from two aspects. By creating large masses, this phenomenon can result instability of the suspension and also reduces the heat transfer by creating areas with no nanoparticles in the liquid and enhancing the thermal resistance. Clustering leads to an augmentation in the local volume fraction which in turn yield greater the viscosity of nanofluids [225]. 
A.K. Patra et al.

International Journal of Thermofluid Science and Technology (2020), Volume 7, Issue 2, Paper No. 070202

\subsection{Aggregation}

Kole and Dey [201] investigated on the effect of aggregation on the viscosity of copper oxide-gear oil nanofluids as a function of $\mathrm{CuO}$ nanoparticles volume fraction and temperature between 10 and $80^{\circ} \mathrm{C}$. They found that aggregation of $\mathrm{CuO}$ nanoparticles and the average aggregate dimension is w7.15. Augmented volume fraction of $\mathrm{CuO}$ nanoparticles in gear oil enhances the viscosity of the nanofluids by nearly 3 times of the base fluid (gear oil). Newtonian feature of the base fluid changes to non-Newtonian one with increasing $\mathrm{CuO}$ volume fraction in the gear oil. Shear thinning behavior becomes prominent for nanofluid with higher $\mathrm{CuO}$ loading.

\subsection{Use time}

Said et al. [226] declared from their study that the use time plays a positive role in the viscosity of $\mathrm{TiO}_{2}$ nanofluids. This is because the viscosity of the stale $\mathrm{TiO}_{2}$ nanofluids after working in a solar collector for one month is lower than that of the fresh samples.

\subsection{Ultrasonication}

Ultrasonication baths or probes are commonly used to physically disperse nanoparticle clusters. Sound energy at an ultrasonication level of $20 \mathrm{kHz}$ and above is applied for a predetermined period of time to disperse nanoparticles into a base fluid and to break clusters of nanoparticles [144]. Mahbubul et al. [17] examined the impact of ultrasonication time on the stability of water-based $\mathrm{Al}_{2} \mathrm{O}_{3}$ nanofluid. They observed that increasing sonication time leads to better colloidal dispersion and a lower viscosity. Sezer and Koc et al. [227] studied the effect of ultrasonication time on viscosity and heat transfer performance of MWCNT nanofluid.

\section{Conclusion}

In this article, a comprehensive, comparative and critical review of the research findings and progress on the viscosity of nanofluids has been presented. Nanofluids and solid suspensions in liquid are widely applicable for various applications, including improvement in the heat transfer of liquids in heat exchangers. It is no doubt that nanoparticles of nonmetals, metals, metal oxides, CNTs and diamonds have been investigated by numerous researchers. Many researchers have investigated the stability and thermophysical properties of nanofluids comprising different type of nanoparticles in different base fluids. The state-ofart review revealed that nanofluids exhibit different rheological behaviors (Newtonian and non-Newtonian) depending on various factors such as shear rate, nanoparticles concentration and size, temperature, surfactant, $\mathrm{pH}$, sonication, dispersion state, particle loading and aggregation. Such pertinent factors also influence the viscosity of nanofluids.

As far as viscosity (a thermophysical property) is concerned, it is the most extensively investigated parameter in the research of nanofluids. In order to extract the best nanofluids the changes of viscosity and the resulting pressure loss must be studied. We must be prudent enough to consider the viscosity as the most significant thermal property of nanofluids since it affects the required pumping energy in potential heat transfer applications. In the existing literature, very high viscosity increments were recorded for nanodiamond and magnetic nanofluids. It is good that a decrease of viscosity was reported due to the addition of different types of nanoparticles in propylene glycol-based fluid. Interestingly, viscosities of all 


\section{A.K. Patra et al.}

International Journal of Thermofluid Science and Technology (2020), Volume 7, Issue 2, Paper No. 070202

nanofluids were found higher than their base fluids and augmented with increasing nanoparticles concentration. It was further revealed from other investigations that enhanced temperature belittles the viscosity of nanofluids. This result could be very useful in hightemperature applications in achieving better thermophysical properties. Investigations on low temperature behavior of nanofluids would be more advantageous to identify the potential low-temperature based applications of nanofluids. Theoretical and experimental studies carried out by previous researchers revealed that the increase in volume fraction and nanoparticles size results in higher nanofluid viscosity (negative influence), while the increase in temperature leads to lower viscosity (positive influence). Any decrease in viscosity of nanofluids with increasing temperature (positive influence) is highly desirable for their application at high temperature environments. Further, addition of surfactants can upgrade dispersion of nanoparticles in the base fluids like dispersion of CNTs in water or oxide particles in the oil. Surfactants act as a bridge to attach nanoparticles to the base fluids in order to avert particles aggregation (lowers the viscosity). Clustering leads to an augmentation in the local volume fraction which in turn yield greater the viscosity of nanofluids. Ultrasonication is implemented to disperse nanoparticles into a base fluid and to break clusters of nanoparticles. It is found from the research that increasing sonication time leads to better colloidal dispersion and a lower viscosity.

Experimental results from the existing literature have been compared with the predictions from different theoretical viscosity models. Classical models were found unable to predict the viscosity of nanofluids. The empirical models proposed by researchers in recent years for nanofluids were based on fitting their own experimental data. However, these empirical models are also not suitable for the predictions of viscosity of other types of nanofluids. Thus, it is of great concern to develop rigorous theoretical models by considering all potential factors for the predictions of viscosity of any type of nanofluids.

It is known that addition of nanoparticles may affect the viscosity which in turn affects the erosion and corrosion behavior of the fluid and the interacting surfaces. However, no study on the erosion and corrosion behavior of nanofluids has been reported yet. In view of industrial applications, the erosion and corrosion behavior of nanofluids in heat transfer systems should be investigated.

Moreover, studies performed on the effects of the said factors are very limited. Thus more studies are to be performed to explore the effect of all these factors and their combined effects on the viscosity of nanofluids. Due to large number of parameters influencing the Rheology of nanofluids, it is also essential to develop a uniform and standardized procedure for the preparation of nanofluids and rheological characterization. In addition to long-time stability, the development of practical use of nanofluids in advanced heat transfer is an eyecatching scientific challenge. Above all, more researches are required to accomplish more favorable outcomes from several kinds of nanofluids.

\section{References}

[1] S U S Choi, Enhancing thermal conductivity of fluids with nanoparticles, ASME Fluids Eng. Division, 231 (1995) 99-105.

[2] S.K. Gupta, S.G. Advani, P. Haq, Role of micro-convection due to non-affine motion of particles in a mono-disperse suspension, Int. J. Heat Mass Transf. 38 (1995) 2945.

[3] J.C. Maxwell, A Treatise on Electricity and Magnetism, Clarendon Press, Oxford, 1873.

[4] V. Srinivas, C.V.K.N.S.N. Moorthy, V. Dedeepya, P.V. Manikanta, V. Satish, Nanofluids with CNTs for automotive applications, Heat Mass Transf. 52 (4) (2016) 701-712. 
A.K. Patra et al.

International Journal of Thermofluid Science and Technology (2020), Volume 7, Issue 2, Paper No. 070202

[5] A. Nasiri, M. Shariaty-Niasar, A. Rashidi, A. Amrollahi, R. Khodafarin, Effect of dispersion method on thermal conductivity and stability of nanofluid, Exp. Thermal Fluid Sci. 35 (4) (2011) 717-723.

[6] Y. Hwang, et al., Stability and thermal conductivity characteristics of nanofluids, Thermochim. Acta 455 (1-2) (2007) 70-74.

[7] X. Wang, X. Li, S. Yang, Influence of $\mathrm{pH}$ and SDBS on the stability and thermal conductivity of nanofluids, Energy Fuel 23 (5) (2009) 2684-2689.

[8] S.K. Das, N. Putra, P. Thiesen, W. Roetzel, Temperature dependence of thermal conductivity enhancement for nanofluids, J. Heat Transfer 125 (4) (2003) 567-574.

[9] M. Chandrasekar, S. Suresh, A. Chandra Bose, Experimental, investigations and theoretical determination of thermal conductivity and viscosity of Al2O3/ water nanofluid, Exp. Therm. Fluid Sci. 34 (2) (2010) 210-216.

[10] A. Meriläinen, A. Seppälä, K. Saari, J. Seitsonen, J. Ruokolainen, S. Puisto, et al., Influence of particle size and shape on turbulent heat transfer characteristics and pressure losses in water-based nanofluids, Int. J. Heat Mass Transf. 61 (2013) 439-448.

[11] S. K. Das, S. U. S. Choi, W. Yu, T. Pradeep, Nanofluids: science and technology. New Jersey: Wiley (2008).

[12] S. M. S. Murshed, K. C. Leong, C. Yang, Thermophysical and electro kinetic properties of nanofluids - a critical review, Appl Therm Eng. 28 (2008) 2109-25.

[13] S. M. S. Murshed, K. C. Leong, C.Yang, Thermophysical properties of nanofluids. In: Sattler $\mathrm{KD}$, editor. Handbook of nanophysics: nanoparticles and quantum dots. Boca Raton: Taylor \& Francis ( 2010).

[14] R. Saidur, K. Y. Leong, H. A. Mohammad, A review on applications and challenges of nanofluids. Renew Sustain Energy Rev. 15 (2011) 1646-68.

[15] N. Sezer, M. A. Atieh, M. Koç, A comprehensive review on synthesis, stability, thermophysical properties, and characterization of nanofluids, Powder Techno. 344 (2019) 404-431.

[16] M. Jarahnejad, E.B. Haghighi, M. Saleemi, N. Nikkam, R. Khodabandeh, B. Palm, et al., Experimental investigation on viscosity of water-based $\mathrm{A} 12 \mathrm{O} 3$ and $\mathrm{TiO} 2$ nanofluids, Rheol. Acta 54 (2015) 411-422.

[17] I. M. Mahbubul, R. Saidur, M. A. Amalina, Latest developments on the viscosity of nanofluids. Int J Heat Mass Transf 55 (2012) 874-85.

[18] P. C. Mishra, S. Mukherjee, S. K. Nayak, A. Panda, A brief review on viscosity of nanofluids. Int Nano Lett 4 (2014) 109-20.

[19] P. N. Nwosu, J. P. Meyer, M. Sharifpur, A review on parametric investigation into nanofluid viscosity models. J Heat Transf 5 (2014) 031008.

[20] R. Prasher, D. Song, J. Wang, P. Phelan, Measurements of nanofluid viscosity and its implications for thermal applications. Appl Phys Lett 89 (2006) 133108.

[21] K.S. Suganthi, K.S. Rajan, Temperature induced changes in $\mathrm{ZnO}$ - water nanofluid: Zeta potential, size distribution and viscosity profiles, Int. J. Heat Mass Transf. 55 (25-26) (2012) 7969-7980.

[22] R. S. Vajjha, D. K. Das, A review and analysis on influence of temperature and concentration of nanofluids on thermophysical properties, heat transfer and pumping power. Int J Heat Mass Transf 55 (2012) 4063-78.

[23] L. S. Sundar, K. V. Sharma, M. T. Naik, M. K. Singh MK, Empirical and theoretical correlations on viscosity of nanofluids: a review. Renew Sustain Energy Rev 25 (2013) 67086.

[24] J. P. Meyer, S. A. Adio, M. Sharifpur, P. N. Nwosu, The viscosity of nanofluids: a review of the theoretical, empirical, and numerical models. Heat Transf Eng 37 (2016) 387-421.

[25] C. Kleinstreuer, Y. Feng, Experimental and theoretical studies of nanofluid thermal conductivity enhancement: a review. Nanoscale Res Lett 6 (2011) 229. 
A.K. Patra et al.

International Journal of Thermofluid Science and Technology (2020), Volume 7, Issue 2, Paper No. 070202

[26] A. K. Sharma, A. K. Tiwari, A. R. Dixit, Rheological behavior of nanofluids: a review. Renew Sustain Energy Rev 53 (2016) 779-91.

[27] K. V. Wong, O. De Leon, Applications of nanofluids: current and future, Adv Mech Eng 2010 (2010) 519659.

[28] Y. Ding, H. Alias, D. Wen, R. A. Williams, Heat transfer of aqueous suspensions of carbon nanotubes (CNT nanofluids). Int J Heat Mass Transf 49 (2006) 240-50.

[29] T. X. Phuoc , M. Massoudi, Experimental observations of the effects of shear rates and particle concentration on the viscosity of $\mathrm{Fe}_{2} \mathrm{O}_{3}$-deionized water nanofluids. Int J Therm Sci 48 (2009) 1294-301.

[30] M. Saleemi, S. Vanapalli, N. Nikkam, M.S. Toprak, M. Muhammed, Classical behavior of alumina nanofluids in antifrogen $\mathrm{N}$ with experimental evidence, J. Nanomater, 2015 (2015) $1-6$.

[31] J. C. Yang, F. C. Li, W. W. Zhou, Y. R. He, B. C. Jiang, Experimental investigation on the thermal conductivity and shear viscosity of viscoelastic-fluid-based nanofluids. Int $\mathrm{J}$ Heat Mass Transf 55 (2012) 3160-6.

[32] B. C. Pak, Y. I. Cho, Hydrodynamic and heat transfer study of dispersed fluids with submicron metallic oxide particles. Exp Heat Transf 11 (1998) 151-70.

[33] S. M. S. Murshed, F. J. V. Santos, Nieto de Castro CA. Investigations of viscosity of silicone oil-based semiconductor nanofluids. J Nanofluid 2 (2013)261-6.

[34] S. Halelfadl, P. Estellé, B. Aladag, N. Doner, T. Maré, Viscosity of carbon nanotubes waterbased nanofluids: influence of concentration and temperature. Int J Therm Sci 71 (2013) 1117.

[35] J. Garg, B. Poudel, M. Chiesa, J. B. Gordon, J. J. Ma, J. B. Wang, Z. F. Ren, Y. T. Kang, H, Ohtani, J. Nanda, G. H. McKinley, G. Chen, Enhanced thermal conductivity and viscosity of copper nanoparticles in ethylene glycol nanofluid. J Appl Phys 103 (2008) 074301.

[36] D. S. Resiga, V. Socoliuc, T. Boros, Borbath T, Marinica O, Han A, Vekas L. The influence of particle clustering on the rheological properties of highly concentrated magnetic nanofluids. J Colloid Interface Sci 373 (2012) 110-5.

[37] W. J. Tseng, K. C. Lin, Rheology and colloidal structure of aqueous $\mathrm{TiO}_{2}$ nanoparticle suspensions. Mater Sci Eng A 355 (2003)186-92.

[38] W. J. Tseng, C. H. Wu, Aggregation, rheology and electrophoretic packing structure of aqueous $\mathrm{Al}_{2} \mathrm{O}_{3}$ nanoparticle suspensions. Acta Mater 50 ( 2002) 3757-66.

[39] M. Kole, T. K. Dey, Effect of aggregation on the viscosity of copper oxide-gear oil nanofluids. Int. J. Therm Sci 50 (2011) 1741-7.

[40] S.M. Sohel Murshed, Patrice Estellé, A state of the art review on viscosity of nanofluids Renewable and Sustainable Energy Reviews 76 (2017) 1134-1152.

[41] H. Chen, Y. Ding, A. Lapkin, X. Fan, Rheological behavior of ethylene glycoltitanate nanotube nanofluids. J Nanopart Res 11 (2009) 1513-20.

[42] D. Kwek, A. Crivoi, F. Duan, Effects of temperature and particle size on the thermal property measurements of Al2O3 - water nanofluids, J. Chem. Eng. Data 55 (12) (2010) 5690-5695.

[43] I. Tavman, A. Turgut, M. Chirtoc, H. P. Schuchmann, S. Tavman, Experimental investigation of viscosity and thermal conductivity of suspensions containing nanosized ceramic particles. Archives of Mater. Sci. 100 (2008) (100-8).

[44] C.T. Nguyen, F. Desgranges, G. Roy, N. Galanis, T. Mare, S. Boucher, H.A. Mints, Temperature and particle-size dependent viscosity data for waterbased nanofluids - hysteresis phenomenon, Int. J. Heat Fluid Flow 28 (2007) 1492-1506.

[45] Lu. Wen-Qiang, Qing-Mei Fan, Study for the particle's scale effect on some thermophysical properties of nanofluids by a simplified molecular dynamics method, Eng. Anal. Boundary Elem. 32 (4) (2008) 282-289. 
A.K. Patra et al.

International Journal of Thermofluid Science and Technology (2020), Volume 7, Issue 2, Paper No. 070202

[46] D. Wen, G. Lin, S. Vafaei, K. Zhang, Review of nanofluids for heat transfer applications, Particuology 7 (2) (2009) 141-150.

[47] L.S. Sundar, E.V. Ramana, M.K. Singh, A.C.M. Sousa, Thermal conductivity and viscosity of stabilized ethylene glycol and water mixture A12O3 nanofluids for heat transfer applications: An experimental study, Int. Comm. Heat Mass Transf. 56(8) (2014) 86-95.

[48] B. LotfizadehDehkordi, S.N. Kazi, M. Hamdi, A. Ghadimi, E. Sadeghinezhad, H.S.C Metselaar, Investigation of viscosity and thermal conductivity of alumina nanofluids with addition of SDBS, Heat Mass Transf. 49 (8) (2013) 1109-1115.

[49] C.K. Kim, G.-J. Lee, C.K. Rhee, A study on heat transfer characteristics of spherical and fibrous alumina nanofluids, Thermochim. Acta 542 (2012) 33-36.

[50] F. Duan, Thermal property measurement of Al2O3-water nanofluids, Smart Nanoparticles Technology, InTech (2012).

[51] M. Leena, S. Srinivasan, Synthesis and ultrasonic investigations of titanium oxide nanofluids, J. Mol. Liq. 206 (2015) 103-109.

[52] Y.J. Hwang, et al., Investigation on characteristics of thermal conductivity enhancement of nanofluids, Curr. Appl. Phys. 6 (6) (2006) 1068-1071.

[53] N. Kumar, S.S. Sonawane, Experimental study of thermal conductivity and convective heat transfer enhancement using $\mathrm{CuO}$ and $\mathrm{TiO}_{2}$ nanoparticles, Int. Commun. Heat Mass Transf. 76(2016) 98-107.

[54] L. Fedele, L. Colla, S. Bobbo, Viscosity and thermal conductivity measurements of waterbased nanofluids containing titanium oxide nanoparticles, International Journal of Refrigeration, 35(5) (2012)1359-1366.

[55] M. Silambarasan, S. Manikandan, K.S. Rajan, Viscosity and thermal conductivity of dispersions of sub-micron $\mathrm{TiO}_{2}$ particles in water prepared by stirred bead milling and ultrasonication, International Journal of Heat and Mass Transfer, 55(25-26) (2012) 7991-8002.

[56] Tun-Ping Teng, Yi-Hsuan, Hung, Ching-Song, Chien-Chih, Chen, Lung-Yue, Jeng, Pressure drop of $\mathrm{TiO}_{2}$ nanofluid in circular pipes, Particuology, 9(5) (2011) 486-491.

[57] K. Yapici, N.K. Cakmak, N. Ilhan, Y. Uludag, Rheological characterization of polyethylene glycol based $\mathrm{TiO}_{2}$ nanofluids, Korea-Australia Rheology Journal, 26(4) (2014) 355-363.

[58] P.K. Das, A.K. Mallik, R. Ganguly, A.K. Santra, Synthesis and characterization of $\mathrm{TiO}_{2}-$ water nanofluids with different surfactants, Int. Commun. Heat Mass Transf. 75 (2016) 341348.

[59] W.H. Azmi, K. Abdul Hamid, R. Mamat, K.V. Sharma, M.S. Mohamad, Effects of working temperature on thermo-physical properties and forced convection heat transfer of $\mathrm{TiO}_{2}$ nanofluids in water - Ethylene glycol mixture, Appl. Therm. Eng. 106 (2016) 1190-1199.

[60] M. Arulprakasajothi, K. Elangovan, K. HemaChandra Reddy, S. Suresh, Heat transfer study of water-based nanofluids containing titanium oxide nanoparticles, Mater. Today Proc. 2 (4-5) (2015) 3648-3655.

[61] S. Sen, V. Govindarajan, C.J. Pelliccione, J.Wang, D.J. Miller, E.V. Timofeeva, Surface modification approach to $\mathrm{TiO}_{2}$ nanofluids with high particle concentration, low viscosity, and electrochemical activity, ACS Appl. Mater. Interfaces 7 (37) (2015) 20538-20547.

[62] H. Chen, Y. Ding, C. Tan, Rheological behaviour of nanofluids, New J. Physics 9(10) (2007) 367.

[63] H. Chen, Y. Ding, Y. He, C. Tan, Rheological behavior of ethylene glycol based titaniananofluids, Chemical Physics Letters, 444(4) (2007) 333-337.

[64] P.K. Namburu, D.P. Kulkarni, D. Misra, D.K. Das, Viscosity of copper oxide nanoparticles dispersed in ethylene glycol and water mixture, Experimental Thermal and Fluid Science, 32(2) (2007) 397-402. 
A.K. Patra et al.

International Journal of Thermofluid Science and Technology (2020), Volume 7, Issue 2, Paper No. 070202

[65] M.J. Pastoriza-Gallego, C. Casanova, J.L. Legido, M.M. Piñeiro, CuO in water nanofluid: influence of particle size and polydispersity on volumetric behavior and viscosity, Fluid Phase Equilib. 300 (2011) 188-196.

[66] V. Prakash, U K Niyogi, R.K. Diwan, Characterization of synthesized copper oxide nanopowders and their use in nanofluids for enhancement of thermal conductivity, Indian $\mathrm{J}$. Pure Appl. Phys. 53 (11) (2015) 753-758.

[67] M.T. Naik, G.R. Janardhana, K.V.K. Reddy, B.S. Reddy, Experimental investigation into rheological property of copper oxide nanoparticles suspended in propylene glycol water based fluids, ARPN J. Eng. Appl. Sci. 5 (2010) 29-34.

[68] K. Kwak, C. Kim, Viscosity and thermal conductivity of copper oxide nanofluid dispersed in ethylene glycol, Kor-Aust Rheol. J. 17 (2005) 35-40

[69] K.R. Priya, K.S. Suganthi, K.S. Rajan, Transport properties of ultra-low concentration CuOwater nanofluids containing non-spherical nanoparticles, Int. J. Heat Mass Transf. 55 (2012) 4734-4743.

[70] M.A. Zennifer, S. Anikandan, K.S. Sughanti, V.L. Vinodhan, K.S. Rajan, Development of $\mathrm{CuO}$-ethylene glycol nanofluids for efficient energy management: assessment of potential for energy recovery, Energy Convers. Manage. 105 (2015) 685-696.

[71] K.S. Suganthi, K.S. Rajan,A formulation strategy for preparation of ZnO-Propylene glycolwater nanofluids with improved transport properties, Int. J. Heat Mass Transf. 71 (2014) 653663.

[72] R. Ikono, et al., Effect of polyacrylic acid addition to improve nano zinc oxide dispersion stability, Int. J. Eng. Technol. IJET-IJENS 12 (06) (2012) 95-99.

[73] S. Witharana, I. Palabiyik, Z. Musina, Y. Ding, Stability of glycol nanofluids - the theory and experiment, Powder Technol. 239 (2013) 72-77.

[74] D. Cabaleiro, L. Colla, F. Agresti, L. Lugo, L. Fedele, Transport properties and heat transfer coefficients of $\mathrm{ZnO} /($ ethylene glycol+water) nanofluids, Int. J. Heat Mass Transf. 89 (2015) 433-443.

[75] S.K. Suganthi, L.V. Vajravel, K.S. Rajan, ZnO-propylene glycol-water nanofluids with improved properties for potential applications in renewable energy and thermal management, Colloids Surfaces A Physicochem. Eng. Asp. 506 (2016) 63-73.

[76] I. Tavman, A. Turgut, M. Chirtoc, K. Hadjov, O. Fudym, S. Tavman, Experimental Study on Thermal Conductivity and Viscosity of Water-Based Nanofluids, Heat Transfer Research, 41(3) (2009) 1-10.

[77] H. Masuda, A. Ebata, K. Teramae, N. Hishinuma, Alteration of Thermal Conductivity and Viscosity of Liquid by Dispersing Ultra-Fine Particles. Dispersion of $\mathrm{Al}_{2} \mathrm{O}_{3}, \mathrm{SiO}_{2}$ and $\mathrm{TiO}_{2}$ Ultra-Fine Particles, Netsu Bussei, 7(4) (1993) 227-233.

[78] D.P. Kulkarni, P.K. Namburu, H.E. Bargar, D.K. Das, Convective Heat Transfer and Fluid Dynamic Characteristics of $\mathrm{SiO}_{2}$ Ethylene Glycol/Water Nanofluid, Heat Transfer Engineering, 29(12) (2008) 1027-1035.

[79] N. Jamshidi, M. Farhadi, D.D. Ganji, K. Sedighi, Experimental investigation on the viscosity ofnanofluids, Int. J. Eng. Transact. B Appl. 25(3) (2012) 201-209.

[80] W. Yu, D.M. France, D.S. Smith, D. Singh, E.V. Timofeeva, J.L. Routbort, Heat transfer to a silicon carbide/water nanofluid, Int. J. Heat Transf. 52(15-16) (2009) 3606-3612.

[81] S.W. Lee, S.D. Park, S. Kang, I.C. Bang, H.K. Ji, Investigation of viscosity and thermal conductivity of $\mathrm{SiC}$ nanofluids for heat transfer applications, Int. J. Heat Transf. 54(1-3) (2011) 433-438.

[82] J.L. Viota, F. González-Caballero, J.D.G. Durán, A.V. Delgado, Study of the colloidal stability of concentrated bimodal magnetic fluids, J. Colloid Interface Sci. 309 (1) (2007) 135-139. 
A.K. Patra et al.

International Journal of Thermofluid Science and Technology (2020), Volume 7, Issue 2, Paper No. 070202

[83] M. Hosseinzadeh, S.Z. Heris, A. Beheshti, M. Shanbedi, Convective heat transfer and friction factor of aqueous $\mathrm{Fe}_{3} \mathrm{O}_{4}$ nanofluid flow under laminar regime, J. Therm. Anal. Calorim. 124 (2) (2016) 827-838.

[84] R.Y. Hong, S.Z. Zhang, Y.P. Han, H.Z. Li, J. Ding, Y. Zheng, Preparation, characterization and application of bilayer surfactant-stabilized ferrofluids, Powder Technol. 170 (1) (2006) $1-11$.

[85] M.K. Nayak, N.S. Akbar, V.S. Pandey, Z.H. Khan, D. Tripathi, 3D free convective MHD flow of nanofluid over permeable linear stretching sheet with thermal radiation, Powd. Technol. 315 (2017) 205-215.

[86] M.K. Nayak, A.K. Abdul Hakeem, O.D. Makinde, Influence of Catteneo-Christov Heat Flux Model on Mixed Convection Flow of Third Grade Nanofluid over an Inclined Stretched Riga Plate, Defect and Diffusion Forum, 387 (2018) 121-134.

[87] M.K. Nayak, M.M Bhatti, O.D. Makinde,N.S. Akbar, Transient Magneto-Squeezing Flow of NaCl-CNP Nanofluid over a Sensor Surface Inspired by Temperature Dependent Viscosity, Defect and Diffusion Forum, 387 (2018) 600-614.

[88] M.K. Nayak, Chemical reaction effect on MHD viscoelastic fluid over a stretching sheet through porous medium, Meccanica, 51 (2016) 1699-1711.

[89] M.K. Nayak, Sachin Shaw, V.S. Pandey, Ali J Chamkha, Combined effects of slip and convective boundary condition on MHD 3D stretched flow of nanofluid through porous media inspired by non-linear thermal radiation, Indian J. Phy., 92(8) (2018) 1017-1028.

[90] M. K. Nayak, N.S. Akbar, V.S. Pandey, Z.H. Khan, D. Tripathi, MHD 3D free convective flow of nanofluid over an exponentially stretching sheet with chemical reaction, Adv. Powder Technol., 28(9) (2017) 2159-2166.

[91] M. K. Nayak, Sachin Shaw, Ali J Chamkha, MHD free convective stretched flow of a radiative nanofluid insprired by variable magnetic field, Arab. J. Sci. Engi., 44(2) (2019) 1269-1282.

[92] M. K. Nayak, I. S. Oyelakin, S. Mondal, S.S. Sen, Impact of the Cattaneo - Christov thermal and solutal diffusion models on the stagnation point slip flow of Walters' B nanofluid past an electromagnetic sheet, Heat Transf. Asian Res., 48(2) (2019) 713-726.

[93] M.K. Nayak, Sachin Shaw, O.D. Makinde, Chemically reacting and radiating nanofluid flow past an exponentially stretching sheet in a porous medium, Indian J. Pure Appl. Phys., 56 (2018) 773-786.

[94] M. K. Nayak, N.S. Akbar, D. Tripathi, V.S. Pandey, Three dimensional MHD flow of nanofluid over an exponential porous stretching sheet with convective boundary conditions, Therm. Sci. Eng. Prog., 3 (2017) 133-140.

[95] M. K. Nayak, MHD 3D flow and heat transfer analysis of nanofluid by shrinking surface inspired by thermal radiation and viscous dissipation, Int. J. Mech. Sci., 125 (2017) 185-193.

[96] A.K. Abdul Hakeem, M. K. Nayak, O. D. Makinde, Effect of exponentially variable viscosity and permeability on Blasius flow of Carreu nanofluid over an electromagnetic plate through a porous medium, Journal of Applied and Computational Mechanics, 5(2) (2019) 390-401.

[97] M. K. Nayak, R. Mehmood, O.D. Makinde, O. Mahian, Ali J. Chamkha, Magnetohydrodynamic flow and heat transfer impact on ZnO-SAE50 nanolubricant flow due to an inclined rotating disk, Journal of Central South University 26 (2019) 1146-1160.

[98] M. Abareshi, E.K. Goharshadi, S.M. Zebarjad, H.K. Fadafan, A. Youssefie, Fabrication, characterization and measurement of thermal conductivity of Fe3O4 nanofluids, J. Magn. Magn. Mater. 322 (24) (2010) 3895-3901.

[99] I. Nkurikiyimfura, Y. Wanga, Z. Pan, Heat transfer enhancement by magnetic nanofluids - a review, Renew. Sust. Energ. Rev. 21 (2013) 548-561.

[100] D. Singh, et al., Use of metallic nanoparticles to improve the thermophysical properties of organic heat transfer fluids used in concentrated solar power, Sol. Energy 105 (2014) 468478. 
A.K. Patra et al.

International Journal of Thermofluid Science and Technology (2020), Volume 7, Issue 2, Paper No. 070202

[101] N. Nikkam, et al., Experimental investigation on thermo-physical properties of copper/ diethylene glycol nano fl uids fabricated via microwave-assisted route, Appl. Therm. Eng. 65 (1-2) (2014) 158-165.

[102] A.K. Jaiswal, et al., Experimental investigation of thermal conduction in copper palladium nanofluids, J. Nanofluids 5 (2016) 1-6.

[103] H. Chen, D. Wen, Ultrasonic-Aided Fabrication of Gold Nanofluids, (2011) 1-8.

[104] L. Wei, P.K. Kuo, R.L. Thomas, T.R. Anthony, W.F. Banholzer, Thermal conductivity of isotopically modified single crystal diamond, Phys. Rev. Lett. 70 (1993) 3764.

[105] L.S. Sundar, M.K. Singh, A.C.M. Sousa, Enhanced thermal properties of nanodiamond nanofluids, Chem. Phys. Lett. 644 (2016) 99-110.

[106] K. Kalidasan, P. Rajesh Kanna, Natural convection on an open square cavity containing diagonally placed heaters and adiabatic square block and filled with hybrid nanofluid of nanodiamond - cobalt oxide/water, Int. Commun. Heat Mass Transf. 81 (2017) 64-71.

[107] G. Z. yła, J. Fal, P. Estellé, The influence of ash content on thermophysical properties of ethylene glycol based graphite/diamonds mixture nanofluids, Diam. Relat. Mater. 74 (2017) 81-89.

[108] A.P. Puzir, A.V. Minakov, A.E. Burov, S.M. Zharkov, N.G. Maksimov, M.I.Pryazhnikov, The effect of silver ions electrolytically introduced into colloidal nanodiamond solution on its viscosity and thermal conductivity, Colloid J. 79 (2017) 258-263.

[109] M. Ghazvini, M.A. Akhavan-Behabadi, E. Rasouli, M. Raisee, Heat transfer properties of nanodiamond-engine oil nanofluid in laminar flow, Heat Transf. Eng. 33 (2012) 525-532.

[110] J.J. Taha-Tijerina, T.N. Narayanan, C.S. Tiwary, K. Lozano, M. Chipara, P.M. Ajayan, Nanodiamond based thermal fluids, ACS Appl. Mater. Interfaces Interfaces 6 (2014) 47784785 .

[111] L. Godson, B. Raja, D.M. Lal, S. Wongwises, Experimental investigation on the thermal conductivity and viscosity of silver-deionized water nanofluid, Exp. Heat Transf. 23 (2010) 317-332.

[112] T. Tyler, O. Shenderova, G. Cunningham, J. Walsh, J. Drobnik, G. McGuire, Thermal transport properties of diamond-based nanofluids and nanocomposites, Diam. Relat. Mater. 15 (2006) 2078-2081.

[113] K.V. Wong, O. De Leon, Applications of nanofluids: Current and future, Adv. Mech. Eng. 2010 (2010) 519659.

[114] P. Naphon, S. Klangchart, S. Wongwises, Numerical investigation on the heat transfer and flow in the mini-fin heat sink for CPU, Int. Commun. Heat Mass Transf. 36 (2009) 834-840.

[115] P. Gunnasegaran, M.Z. Abdullah, M.Z. Yusoff, Experimental analysis and FEM simulation of loop heat charged with diamond nanofluid for desktop PC cooling, IOP Conf. Ser. Mater. Sci. Eng. 88 (2015) 12038. http://stacks.iop.org/1757-899X/88/i=1/a=012038.

[116] C. Choi, H.S. Yoo, J.M. Oh, Preparation and heat transfer properties of nanoparticle-intransformer oil dispersions as advanced energy-efficient coolants, Curr. Appl. Phys. 8 (2008) $710-712$.

[117] H.B. Ma, C. Wilson, B. Borgmeyer, K. Park, Q. Yu, S.U.S. Choi, M. Tirumala, Effect of nanofluid on the heat transport capability in an oscillating heat pipe, Appl. Phys. Lett. 88 (2006) 143116.

[118] B. Shen, A.J. Shih, S.C. Tung, Application of nanofluids in minimum quantity lubrication grinding, Tribol. Lubr. Technol. 65 (2009) 73.

[119] S. Lijima, Helical microtubules of graphitic carbon, Nature 354 (1991) 56-58.

[120] S.J. Tans, A.R.M. Verschueren, C. Dekker, Room-temperature transistor based on a single carbon nanotube, Nature 393 (1998) 49-52.

[121] Liu Fan, Liu Cong, Cheng, Dresselhaus, Hydrogen storage in single-walled carbon nanotubes at room temperature, Science 286 (5442) (1999) 1127-1129. 
A.K. Patra et al.

International Journal of Thermofluid Science and Technology (2020), Volume 7, Issue 2, Paper No. 070202

[122] Fan, Chapline, Franklin, Tombler, Cassell, Dai, Self-oriented regular arrays of carbon nanotubes and their field emission properties, Science 283 (5401) (1999) 512-514.

[123] S. Iijima, T. Ichihashi, Single-shell carbon nanotubes of 1-nm diameter, Nature 363 (6430) (1993) 603-605.

[124] S.S.J. Aravind, P. Baskar, T.T. Baby, R.K. Sabareesh, S. Das, S. Ramaprabhu, Investigation of structural stability, dispersion, viscosity, and conductive heat transfer properties of functionalized carbon nanotube based nanofluids, J. Phys. Chem. C 115 (34) (2011) 1673716744.

[125] K. Esumi, M. Ishigami, A. Nakajima, K. Sawada, H. Honda, Chemical treatment of carbon nanotubes, Carbon N. Y. 34 (2) (1996) 279-281.

[126] S. Jana, A. Salehi-Khojin, W.-H. Zhong, Enhancement of fluid thermal conductivity by the addition of single and hybrid nano-additives, Thermochim. Acta 462 (1-2) (2007) 45-55.

[127] H. Xie, H. Lee, W. Youn, M. Choi, Nanofluids containing multiwalled carbon nanotubes and their enhanced thermal conductivities, J. Appl. Phys. 94 (8) (2003) 4967.

[128] Q. Chen, C. Saltiel, S. Manickavasagam, L.S. Schadler, R.W. Siegel, H. Yang, Aggregation behavior of single-walled carbon nanotubes in dilute aqueous suspension, J. Colloid Interface Sci. 280 (1) (2004) 91-97.

[129] J. Ponmozhi, et al., Thermodynamic and transport properties of CNT-water based nanofluids, J. Nanopart. Res. 11 (2010) 101-106.

[130] B. Lamas, B. Abreu, A. Fonseca, N. Martins, M. Oliveira, Assessing colloidal stability of long term MWCNT based nanofluids, J. Colloid Interface Sci. 381 (1) (Sep. 2012) 17-23.

[131] M. Xing, J. Yu, R. Wang, Thermo-physical properties of water-based single-walled carbon nanotube nanofluid as advanced coolant, Appl. Therm. Eng. 87 (2015) 344-351.

[132] M.A. Sabiha, R.M. Mostafizur, R. Saidur, S. Mekhilef, Experimental investigation on thermo physical properties of single walled carbon nanotube nanofluids, Int. J. Heat Mass Transf. 93 (2016) 862-871.

[133] N. Singh, G. Chand, S. Kanagaraj, Investigation of thermal conductivity and viscosity of carbon nanotubes-ethylene glycol nanofluids, Heat Transf. Eng. 33 (9) (2012) 821-827.

[134] L. Chen, H. Xie, Y. Li, W. Yu, Nanofluids containing carbon nanotubes treated by mechanochemical reaction, Thermochimica Acta, 477(1-2) (2008) 21-24.

[135] T.X. Phuoc, M. Massoudi, R.H. Chen, Viscosity and thermal conductivity of nanofluids containing multi-walled carbon nanotubes stabilized by chitosan, International Journal of Thermal Sciences, 50(1) (2011) 12-18

[136] G.H. Ko, K. Heo, K. Lee, D.S. Kim, C. Kim, Y. Sohn, M. Choi, An experimental study on the pressure drop of nanofluids containing carbon nanotubes in a horizontal tube, International Journal of Heat and Mass Transfer, 50(23-24) (2007) 4749-4753.

[137] P. Garg, J.L. Alvarado, C. Marsh, T.A. Carlson, D.A. Kessler, K. Annamalai, An experimental study on the effect of ultrasonication on viscosity and heat transfer performance of multi-wall carbon nanotube-based aqueous nanofluids, International Journal of Heat and Mass Transfer, 52(21-22) (2009) 5090-5101.

[138] S. Halelfadl, P. Estellé, B. Aladag, N. Doner, T. Maré, Viscosity of carbon nanotubes waterbased nanofluids: Influence of concentration and temperature, International Journal of Thermal Sciences, 71(3) (2013) 111-117.

[139] H. Khodadadi, S. Aghakhani, H. Majd, R. Kalbasi, S. Wongwises, M. Afrand, A comprehensive review on rheological behavior of mono and hybrid nanofluids: Effective parameters and predictive correlations, Int. J. of Heat Mass Transfer 127 (2018) 997-1012.

[140] K.S. Indhuja, S. Suganthi, K.S. Manikandan Rajan, Viscosity and thermal conductivity of dispersions of gum arabic capped MWCNTin water: influence of MWCNT concentration and temperature, J. Taiwan Inst. Chem. Eng. 44 (2013) 474-479.

[141] Y. Yang, E.A. Grulke, Z.G. Zhang, G. Wu, Thermal and rheological properties of carbon nanotube-in-oil dispersions, J. Appl. Phys. 99 (2006) 114307. 
A.K. Patra et al.

International Journal of Thermofluid Science and Technology (2020), Volume 7, Issue 2, Paper No. 070202

[142] I.A. Kinloch, S.A. Roberts, A.H. Windle, A rheological study of concentrated aqueous nanotube dispersions, Polymer 43 (2002) 7483-7491.

[143] G. Vakili-Nezhaada, A. Dorany, Effect of single-walled carbon nanotube on the viscosity of lubricants, Energy Procedia 14 (2012) 512-517.

[144] B. Ruan, A.M. Jacobi, Ultrasonication effects on thermal and rheological properties of carbon nanotube suspensions, Nanoscale Res. Lett. 7 (2012).

[145] L. Yang, K. Du, Y.H. Ding, B. Cheng, Y.J. Li, Viscosity-prediction models of ammonia water nanofluids based on various dispersion types, Powder Technology, 215(1) (2012) 210218.

[146] P. Garg, J.L. Alvarado, C. Marsh, T.A. Carlson, D.A. Kessler, K. Annamalai, An experimental study on the effect of ultrasonication on viscosity and heat transfer performance of multi-wall carbon nanotube-based aqueous nanofluids, Int. J. Heat Mass Transf. 52 (2009) 5090-5101.

[147] H. Xie, L. Chen, Adjustable thermal conductivity in carbon nanotube nanofluids, Phys. Lett. A 373 (21) (2009) 1861-1864.

[148] S. Harish, K. Ishikawa, E. Einarsson, S. Aikawa, T. Inoue, P. Zhao, M. Watanabe, S. Chiashi, J. Shiomi, S. Maruyama, Temperature dependent thermal conductivity increase of aqueous nanofluid with single walled carbon nanotube inclusion, Mater. Exp. 2 (2012) 213-223.

[149] P. Estellé, S. Halelfadl, T. Maré, Lignin as dispersant for water-based carbon nanotubes nanofluids: impact on viscosity and thermal conductivity, Int. Commun. Heat Mass Transf. 57 (2014) 8-12.

[150] R. Sadri, G. Ahmadi, H. Togun, M. Dahari, S.N. Kazi, E. Sadeghinezhad, N. Zubir, An experimental study on thermal conductivity and viscosity of nanofluids containing carbon nanotubes, Nanoscale Res. Lett. 9 (2014) 151.

[151] L. Maillaud, P. Poulin, M. Pasquali, C. Zakri, Effect of the rheological properties of carbon nanotube dispersions on the processing and properties of transparent conductive electrodes, Langmuir 31 (2015) 5928-5934.

[152] M. Abareshi, S.H. Sajjadi, S.M. Zebarjad, E.K. Goharshadi, Fabrication, characterization, and measurement of viscosity of $\alpha$-Fe2O3 -glycerol nanofluids, J. Mol. Liq. 163(1) (2011) 27-32.

[153] V. Zhelezny, N. Lukianov, O.Y. Khliyeva, A. Nikulina, A. Melnyk, A complex investigation of the nanofluids R600a-mineral oil-Al2O3 and R600a-mineral oil-TiO2. thermophysical properties, Int. J. Refrig. 74 (2017) 488-504.

[154] T. Kourti, Turbidimetry in particle size analysis, Encyclopedia of analytical chemistry: Applications, Theory and Instrumentation (2006).

[155] G. Crawley, M. Cournil, D. Di Benedetto, Size analysis of fine particle suspensions by spectral turbidimetry: potential and limits, Powder Technol. 91 (3) (1997) 197-208.

[156] A. Nikulin, A.S. Moita, A.L.N. Moreira, S.M.S. Murshed, A. Huminic, Y. Grosu, A. Faik, J. Nieto-Maestre, O. Khliyeva, Effect of $\mathrm{Al}_{2} \mathrm{O}_{3}$ nanoparticles on laminar, transient and turbulent flow of isopropyl alcohol, Int. J. Heat Mass Transf. 130 (2019) 1032-1044.

[157] H.T. Zhu, C.J. Li, D.X. Wu, C.Y. Zhang, Y.S. Yin, Preparation, characterization, viscosity and thermal conductivity of $\mathrm{CaCO} 3$ aqueous nanofluids, Science China Technological Sciences, 53(2) (2010) 360-368.

[158] G. Zyła, J. Grzywa, A. Witek, M. Cholewa, Influence of anisotropic pressure on viscosity and electrorheology of diethylene glycol-based MgAl2O4 nanofluids, Nanoscale Research Letters, 9(1) (2014) 1-13.

[159] A. Huminic, G.Huminic, C. Fleaca, F. Dumitrache, I. Morjan, Thermal conductivity, viscosity and surface tension of nanofluids based on $\mathrm{FeC}$ nanoparticles, Powder Technology, $284(2015) 78-84$.

[160] X. Wang, X. Xu, S.U.S. Choi, Thermal conductivity of nanoparticle-fluid mixture, J. Thermophys. Heat Transfer 13 (4) (1999) 474-480. 
A.K. Patra et al.

International Journal of Thermofluid Science and Technology (2020), Volume 7, Issue 2, Paper No. 070202

[161] C. Nguyen, F. Desgranges, N. Galanis, G. Roy, T. Marc, S. Boucher, H. Angue Mintsa, Viscosity data for Al2O3-water nanofluid-hysteresis: is heat transfer enhancement using nanofluids reliable, Int. J. Therm. Sci. 47 (2) (2008) 103-111.

[162] K. Anoop, S. Kabelac, T. Sundararajan, S.K. Das, Rheological and flow characteristics of nanofluids: influence of electroviscous effects and particle agglomeration, J. Appl. Phys. 106 (3) (2009) 907-909.

[163] A.J. Schmidt, M. Chiesa, D.H. Torchinsky, J.A. Johnson, A. Boustani, G.H. Mckinley, K.A. Nelson, G. Chen, Experimental investigation of nanofluid shear and longitudinal viscosities, Appl. Phys. Lett. 92 (2008) 244107.

[164] Q. He, M. Tong, Y. Liu, Experimental study on viscosities of $\mathrm{TiO}_{2}-\mathrm{H}_{2} \mathrm{O}$ nanofluids, Chem. Ind. Eng. Prog. 28(1) (2009) 37-40.

[165] Q. He, Z. Zheng, Experimental Study on Nano-fluids viscosity in Low-temperature Phase Transition Storage, Chem. Eng. Machi. 38 (2011) 420-422.

[166] Z.Y. Ling, D.J. Sun, Z.Q. Zhang, J.N. Ding, G.G. Cheng, L. Qian, R. Zhang, Effect of temperature and nanoparticle concentration on the viscosity of nanofluids, Gongneng Cailiao/journal of Functional Materials, 44(1) (2013) 92-95.

[167] H. Chen, Y. Ding, Y. He, C. Tan, Rheological behaviour of ethylene glycol based titania nanofluids Chem. Phys. Lett. 444(4) (2007) 333-337.

[168] T. Yiamsawas, O. Mahian, A.S. Dalkilic, S. Kaewnai, S. Wongwises, Experimental studies on the viscosity of $\mathrm{TiO}_{2}$ and $\mathrm{Al}_{2} \mathrm{O}_{3}$ nanoparticles suspended in a mixture of ethylene glycol and water for high temperature applications, Applied Energy, 111(4) (2013) 40-45.

[169] W.J. Tseng, C.N. Chen, Effect of polymeric dispersant on rheological behavior of nickelterpineol suspensions, Mat. Sci. Engi. A, 347(1-2) (2003) 145-153.

[170] A. Einstein, A new determination of molecular dimensions, Ann. Phys. 19 (1906) 289-306.

[171] H.C. Brinkman, The Viscosity of Concentrated Suspensions and Solutions, Journal of Chemical Physics, 20(4) (1952) 571-571.

[172] H. De Bruijn, The viscosity of suspensions of spherical particles. (The fundamental $\eta-c$ and $\varphi$ relations), Recueil des Travaux Chimiques des Pays-Bas, 61(12) (2015) 863-874.

[173] G.K. Batchelor, The effect of Brownian motion on the bulk stress in a suspension of spherical particles, Journal of Fluid Mechanics, 83(1) (1977) 97-117.

[174] V. Vand, Theory of Viscosity of Concentrated Suspensions, Nature, 155(3934) (1945) 364365 .

[175] L. Lundgren, Slow flow through stationary random beds and suspensions of spheres, Journal of Fluid Mechanics, 51(2) (1972) 273-299.

[176] S.S. Guo, Z.Y. Luo, W. Tao, J.F. Zhao, K.F. Cen, Viscosity of Monodisperse Silica Nanofluids, Bulletin of the Chinese Ceramic Society, 25(5) (2006) 52-55.

[177] A.L. Graham, On the viscosity of suspensions of solid spheres, Flow, Turbulence and Combustion, 37(3) (1981) 275-286.

[178] D.G. Thomas, Transport characteristics of suspension: VIII. A note on the viscosity of Newtonian suspensions of uniform spherical particles, Journal of Colloid Science, 20(3) (1965) 267-277.

[179] I.M. Krieger, T.J. Dougherty, A Mechanism for Non - Newtonian Flow in Suspensions of Rigid Spheres, Transactions of The Society of Rheology 3(1) (1959) 137-152.

[180] D. J. Jeffrey, A. Acrivos, The rheological properties of suspensions of rigid particles. AIChE J 22 (1976) 417-32.

[181] R.D. Selvakumar, S. Dhinakaran, Effective viscosity of nanofluids - A modified KriegerDougherty model based on particle size distribution (PSD) analysis, Journal of Molecular Liquids, 225 (2016) 20-27.

[182] N.A. Frankel, A. Acrivos, On the viscosity of a concentrated suspension of solid spheres, Chemical Engineering Science, 1967 22(6) 847-853. 
A.K. Patra et al.

International Journal of Thermofluid Science and Technology (2020), Volume 7, Issue 2, Paper No. 070202

[183] T. Kitano, T. Kataoka, T. Shirota, An empirical equation of the relative viscosity of polymer melts filled with various inorganic fillers, Rheologica Acta, 20(2) (1981) 207-209.

[184] L.E. Nielsen, Generalized Equation for the Elastic Moduli of Composite Materials, Journal of Applied Physics, 41(11) (1970) 4626-4627.

[185] N. Masoumi, N. Sohrabi, A. Behzadmehr, A new model for calculating the effective viscosity of nanofluids, Journal of Physics D: Applied Physics, 42(5) (2009) 055501.

[186] M. Mooney, A shearing disk plastometer for unvulcanized rubber, Ind. Eng Chem. Anal. Ed 6 (1934) 147-151.

[187] V.H. Eilers, Die viskocitat von emulsionen hochviskoser stoffe als funktion der onzentration, Kolloid Z. 97 (1941) 313-321.

[188] N. Saito, Concentration dependence of the viscosity of high polymer solutions, J. Phys. Soc. Jpn, I. 5 (1950) 4-8.

[189] M. Hemmat Esfe, M. Afrand, S.H. Rostamian, D. Toghraie, Examination of rheological behavior of MWCNTs/ZnO-SAE40 hybridnano-lubricants under various temperatures and solid volume fractions, Exp. Therm Fluid Sci. 80 (2017) 384-390.

[190] M. Afrand, K.N. Najafabadi, M. Akbari, Effects of temperature and solid volume fraction on viscosity of SiO2-MWCNTs/SAE40 hybrid nanofluid as a coolant and lubricant in heat engines, Appl. Therm. Eng. (2016).

[191] M. Hemmat Esfe, M. Afrand, D. Toghraie, H. Rostamian, An experimental study on viscosity of alumina-engine oil: effects of temperature and 2 nanoparticles concentration, Int. Commun. Heat Mass Transfer (2016).

[192] D. Toghraie, S.M. Alempour, M. Afrand, Experimental determination of viscosity of waterbased magnetite nanofluid for application in heating and cooling systems, J. Magnet. Magnet. Mater. (2016).

[193] S.E.B. Maiga, C.T. Nguyen, N. Galanis, G. Roy, Heat transfer behaviours of nanofluids in a uniformly heated tube, Superlatt. Microstruct. 35 (3) (2004) 543-557.

[194] M.J. Kao, H. Chang, Y.-Y. Wu, T.-T. Tsung, H.-M. Lin, Producing aluminum oxide brake nanofluids using plasma charging system, J. Chin. Soc. Mech. Eng. 28 (2) (2007) 123-131.

[195] E. Abu-Nada, Effects of variable viscosity and thermal conductivity of $\mathrm{Al}_{2} \mathrm{O}_{3}$ - water nanofluid on heat transfer enhancement in natural convection, Int. J. Heat Fluid Flow 30 (2009) 679-690.

[196] W. Duangthongsuk, S. Wongwises, Measurement of temperature dependent thermal conductivity and viscosity of TiO2-water nanofluids, Exp. Therm Fluid Sci. 33 (2009) 706714.

[197] D. Wen, G. Lin, S. Vafaei, K. Zhang, Review of nanofluids for heat transfer applications, Particuology 7 (2) (2009) 141-150.

[198] D. Wu, H. Zhu, L. Wang, L. Liu, Critical issues in nanofluids preparation, characterization and thermal conductivity, Curr. Nanosci. 5 (1) (2009) 103-112.

[199] K. Bashirnezhad, et al., Viscosity of nanofluids: a review of recent experimental studies, Int. Commun. Heat Mass Transf. 73 (2016) 114-123.

[200] M. Behi, S.A. Mirmohammadi, Investigation on thermal conductivity, viscosity and stability of nanofluids, Dep. Energy Technol. R. Inst. Technol. (KTH), Stock. Sweden (2012).

[201] J. Buongiorno, Convective Transport in Nanofluids, Journal of Heat Transfer, 128(3) (2006) 240-250.

[202] U. Rea, T. Mckrell, L.W. Hu, J. Buongiorno, Laminar convective heat transfer and viscous pressure loss of alumina-water and zirconia-water nanofluids, Int. J. Heat Mass Transf. 52(7-8) (2009) 2042-2048.

[203] M.T. Naik, L.S. Sundar, Investigation into Thermophysical Properties of Glycol based CuO Nanofluid for Heat Transfer Applications, World Academy of Sci. Engi. Technol. 59 (2011) 440-446. 
A.K. Patra et al.

International Journal of Thermofluid Science and Technology (2020), Volume 7, Issue 2, Paper No. 070202

[204] L.S. Sundar, E.V. Ramana, M.K. Singh, A.C.M.D. Sousa, Viscosity of low volume concentrations of magnetic $\mathrm{Fe} 3 \mathrm{O} 4$ nanoparticles dispersed in ethylene glycol and water mixture, Chem. Phys. Lett. 554(6) (2012) 236-242.

[205] H. Brenner, D.W. Condiff, Transport mechanics in systems of orientable particles. IV. Convective transport, J. Colloid Interf. Sci. 47(1) (1974) 199-264.

[206] S. Bobbo, L. Fedele, A. Benetti, L. Colla, M. Fabrizio, C. Pagura, S. Barison, Viscosity of water based SWCNH and TiO2 nanofluids, Exp. Therm. Fluid Sci. 36(1) (2012) 65-71.

[207] G. Vakili-Nezhaad, A. Dorany, Effect of Single-Walled Carbon Nanotube on the Viscosity of Lubricants, Energy Procedia, 14(18) (2012) 512-517.

[208] K.V. Sharma, P.K. Sarm, W.H. Azmi, R. Mamat, K. Kadirgama, Correlations to predict friction and forced convection heat transfer coefficients of water based nanofluids for turbulent flow in a tube, Int. J. Microscale Nanoscale Therm. Fluid Transp. Phenomena, 3(4) (2012) 283-307.

[209] Y. He, Y. Jin, H. Chen, Y. Ding, D. Cang, H. Lu, Heat transfer and flow behavior of aqueous suspensions of $\mathrm{TiO} 2$ nanoparticles (nanofluids) flowing upward through a vertical pipe, Int. J. Heat Mass Transf. 50 (11-12) (2007) 2272-2281.

[210] Lu. Wen-Qiang, Qing-Mei Fan, Study for the particle's scale effect on some thermophysical properties of nanofluids by a simplified molecular dynamics method, Eng. Anal. Boundary Elem. 32 (4) (2008) 282-289.

[211] K. Khanafer, K. Vafai, A critical synthesis of thermophysical characteristics of nanofluids, Int. J. Heat Mass Transf. 54 (19-20) (2011) 4410-4428.

[212] D. Wen, G. Lin, S. Vafaei, K. Zhang, Review of nanofluids for heat transfer applications, Particuology 7 (2) (2009) 141-150.

[213] S. Ozerinc, S. Kakac, A.G. Yazicioglu, M. Nanofluid, Enhanced thermal conductivity of nanofluids: a state-of-the-art review, Microfluid. Nanofluid. 8 (2) (2010) 145-170.

[214] M. Farbod, R. Kouhpeymani Asl, A.R. Noghreh abadi, Morphology dependence of thermal and rheological properties of oil-based nanofluids of $\mathrm{CuO}$ nanostructures, Colloids Surfaces A Physicochem. Eng. Asp. 474 (2015) 71-75.

[215] M.A.K. Abdelhalim, M.M. Mady, M.M. Ghannam, Rheological and dielectric properties of different gold nanoparticle sizes, Lipids Health Dis. 10 (2011) 208.

[216] N. Putra, W. Roetzel, S.K. Das, Natural convection of nano-fluids, Heat Mass Transf. 39 (2003) 8-9.

[217] G.A. Oliveira, E.P. Bandarra Filho, D. Wen, Synthesis and characterization of silver/water nanofluids, High Press. 43 (2014) 69-83.

[218] E.V. Timofeeva, D.S. Smith, W. Yu, D.M. France, D. Singh, J.L. Routbort, Particle size and interfacial effects on thermo-physical and heat transfer characteristics of water-based a-SiC nanofluids, Nanotechnology 21 (2010) 215703.

[219] A. Meriläinen, A. Seppälä, K. Saari, J. Seitsonen, J. Ruokolainen, S. Puisto, et al., Influence of particle size and shape on turbulent heat transfer characteristics and pressure losses in water-based nanofluids, Int. J. Heat Mass Transf. 61 (2013) 439-448.

[220] A.V. Minakov, D.V. Guzei, M.I. Pryazhnikov, V.A. Zhigarev, V.Y. Rudyak, Study of turbulent heat transfer of the nanofluids in a cylindrical channel, Int. J. Heat Mass. Transf. 102 (2016) 745-755.

[221] J. Chevalier, O. Tillement, F. Ayela, Rheological properties of nanofluids flowing through microchannels, Appl. Phys. Lett. 91 (2007) 2007-2009.

[222] W. Xian-Ju, L. Xin-Fang, Influence of pH on nanofluids' viscosity and thermal conductivity, Chin. Phys. Lett. 26 (5) (2009), 056601.

[223] H. Xie, L. Cheri, Q. Wu, Measurements of the viscosity of suspensions (nanofluids) containing nanosized $\mathrm{Al}_{2} \mathrm{O}_{3}$ particles, High Temp. High Press. 37 (2) (2008) 127-135.

[224] L. Vandsburger, Synthesis and Covalent Surface Modification of Carbon Nanotubes for Preparation of Stabilized Nanofluid Suspensions, McGill University, Canada (2009). 
A.K. Patra et al.

International Journal of Thermofluid Science and Technology (2020), Volume 7, Issue 2, Paper No. 070202

[225] R. Saidur Ghadimi, Metselaar, A review of nanofluid stability properties and characterization in stationary conditions, Int. J. Heat Mass Transf. 54 (17) (2011) 4051-4168.

[226] Z. Said, M.A. Sabiha, R. Saidur, A. Hepbasli, N.A. Rahim, S. Mekhilef, T.A. Ward, Performance enhancement of a Flat Plate Solar collector using Titanium dioxide nanofluid and Polyethylene Glycol dispersant, J. Cleaner Production, 92 (2015) 343-353.

[227] N. Sezer, M. Koç, Dispersion Stability of CNT and CNT/Metal-based Nanofluids, Int. Conference on Thermal Engineering: Theory and Applications (2018) 1-4. 